\title{
Thermophysical Properties of Sodium Nitrate and Sodium Chloride Solutions and Their Effects on Fluid Flow in Unsaturated Media
}

\author{
Tianfu Xu and Karsten Pruess \\ Earth Sciences Division, Lawrence Berkeley National Laboratory, University of \\ California, Berkeley, CA 94720
}

\begin{abstract}
Understanding movement of saline sodium nitrate $\left(\mathrm{NaNO}_{3}\right)$ waste solutions is important for assessing the contaminant migration near leaking waste storage tanks in the unsaturated zone at the Hanford site (Washington, USA). The purpose of this study is to contribute a basic understanding of effects of the thermophysical behavior of $\mathrm{NaNO}_{3}$ solutions on fluid flow in unsaturated media. We first present mathematical expressions for the dependence of density, viscosity, solubility and vapor pressure of $\mathrm{NaNO}_{3}$ solutions on both salt concentration and temperature, which were determined by fitting from published measured data. Because the previous studies of thermophysical behavior of sodium chloride $(\mathrm{NaCl})$ solutions can provide a basis for those of $\mathrm{NaNO}_{3}$ solutions, we also present a comparison of thermophysical properties of both salt solutions. We have implemented the functional thermophysical properties of $\mathrm{NaNO}_{3}$ solutions into a new TOUGH2 equation-of-state module EWASG_NaNO 3 , which is modified from a previous TOUGH2 equation-of-state module EWASG for $\mathrm{NaCl}$. Using the simulation tool, we have investigated effects of the thermophysical properties on fluid flow in unsaturated media. The effect of density and viscosity of saline solutions has been long recognized. Here we focus our attention on the effect of vapor pressure lowering due to salinity. We present simulations of a one-dimensional problem to study this salinitydriven fluid flow. A number of simulations were performed using different values of thermal conductivity, permeability, and temperature, to illustrate conditions and parameters controlling these processes. Results indicate that heat conduction plays a very important role in this salinity-driven vapor diffusion by maintaining a nearly constant temperature. The smaller the permeability, the more water is transferred into the saline environment. Effects of permeability on water flow are also complicated by effects of capillary pressure and tortuosity. The higher the temperature, the more significant the salinity driven fluid flow.
\end{abstract}

Key words: thermophysical property, sodium nitrate, sodium chloride, vapor diffusion, fluid flow, unsaturated media, numerical simulation. 


\section{Introduction}

At the U.S. Department of Energy's Hanford site (Richland, Washington), highly saline waste solutions (often $>5 \mathrm{~m} \mathrm{NaNO}_{3}$ ) are stored in 149 single-shell and 28 doubleshell underground tanks. Sixty-seven single-shell tanks have been identified as leaking and have released an estimated 1 million gallons of the mixed waste solutions into the vadose (unsaturated) zone sediments surrounding the tanks. Understanding movement of these saline $\mathrm{NaNO}_{3}$ solutions is important for assessing the contaminant migration and developing remedial actions. A number of aspects affect the mobility of waste solutions, including fluid thermophysical and medium hydrological properties. The purpose of this report is to (1) present some thermophysical properties (such as density, viscosity, and vapor pressure) of the saline solutions, and (2) investigate their effects on liquid flow in unsaturated media. The leaked fluids react strongly with the sediments and very likely alter their hydrological and sorptive properties. These reactive chemical effects are beyond the scope of this report.

Weisbrod et al. (2000) performed an experiment for infiltration of highly saline solutions in 2-D chambers using a light transmission technique and four different grades of silica sand. The solutions that were used include: $5 \mathrm{~m} \mathrm{NaNO}, 5 \mathrm{~m} \mathrm{NaNO} 3+2 \%$ methanol, and pure water, as well as varying concentrations of $\mathrm{NaNO}_{3}$. Their results showed that transport of water from pre-wetted sand into the highly saline $\mathrm{NaNO}_{3}$ solution plumes is a significant process, taking place within hours. They also suggested that surface tension plays an important role in infiltration rate and finger geometry. A number of references on thermophysical properties of $\mathrm{NaNO}_{3}$ solutions have been available. Mahiuddin and Ismail (1996) reported some measured data for density of 
sodium nitrate solutions. Apelblat and Korin (1998) presented experimental data for sodium nitrate solubility and vapor pressure.

Thermophysical properties of sodium chloride $(\mathrm{NaCl})$ solutions have been better understood than those of $\mathrm{NaNO}_{3}$ solutions. NaCl-rich waters are commonly present in the subsurface such as geothermal reservoirs, deep aquifers, and salt water intrusion regions. Previous studies of thermophysical behavior of $\mathrm{NaCl}$ solutions can provide a basis for those of $\mathrm{NaNO}_{3}$ solutions. A comparison of thermophysical properties of both salt solutions is useful for the present study. Battistelli et al. (1997) present a comprehensive treatment of thermophysical properties of multiphase mixtures of $\mathrm{H}_{2} \mathrm{O}-\mathrm{NaCl}-\mathrm{CO}_{2}$ using data from the literature. They implemented the functional relationships of salinity and temperature dependent thermophysical properties into an equation-of-state (EOS) module, EWASG, for the general-purpose multi-phase fluid and heat flow simulator TOUGH2 (Pruess et al., 1999). The EWASG module is able to describe three-component mixtures of water, sodium chloride, and a slightly soluble non-condensible gas (NCG) over a wide range of pressures, temperatures, and compositions.

In this report, we first present mathematical expressions for the dependence of density, viscosity, solubility and vapor pressure of $\mathrm{NaNO}_{3}$ solutions on salt concentration and temperature, which were fitted from measured data reported by Mahiuddin and Ismail (1996) and Apelblat and Korin (1998). Then we present a comparison of thermophysical properties of both salt solutions, based on the expressions presented here for $\mathrm{NaNO}_{3}$ and those presented by Battistelli et al. (1997) for $\mathrm{NaCl}$. After that, we give a brief description of implementing the $\mathrm{NaNO}_{3}$ thermophysical properties into an equationof-state module for the TOUGH2 simulator. 
The numerical simulation tool is then used to investigate the effect of the thermophysical properties on fluid flow in unsaturated media. Because the objective of this study is to develop a general understanding of the thermophysical behavior of $\mathrm{NaNO}_{3}$ solutions, we do not use specific hydrogeologic details at the Hanford site. The effect of density and viscosity of saline solutions on fluid flow has been long recognized. Here we focus our attention on the effect of vapor pressure lowering due to salinity. The experimental results of Weisbrod et al. (2000) show that the pure water is transferred into the saline environment. It is hypothesized that the main mechanism for this is diffusion of water vapor from uncontaminated soil to the highly saline contaminated plume, whose vapor pressure is reduced. We present simulations of a one-dimensional problem to study this multiphase process driven by salinity gradients. A number of simulations were performed using different values of thermal conductivity, permeability, and temperature, in order to (1) examine the effect of vapor pressure lowering due to salinity on vapor and water flow, and (2) illustrate conditions and parameters such as heat conductivity, permeability, and temperature controlling these processes. 


\section{Thermophysical Properties of Sodium Nitrate}

\subsection{Density}

Mahiuddin and Ismail (1996) reported some measured data for density of sodium nitrate $\left(\mathrm{NaNO}_{3}\right)$ solutions that are linear functions of both temperature $(293 \leq \mathrm{T}(\mathrm{K}) \leq$ 313.0) and molarity $(0.1113 \leq \mathrm{c}(\mathrm{mol} / \mathrm{l}) \leq 7.354)$. The variation on molality, $\mathrm{m}(\mathrm{mol} / \mathrm{kg}$ $\mathrm{H}_{2} \mathrm{O}$ ), exhibits a non-linear relationship. They also compared their data with available data reported by other investigators in the concentration range of $0.1186 \leq \mathrm{m} \leq 7.840$ at $293 \mathrm{~K}$ (Weast, 1985) and $0.050 \leq \mathrm{m} \leq 8.000$ at $288 \mathrm{~K} \leq \mathrm{T} \leq 328 \mathrm{~K}$ (Isono, 1984). It was found that the experimental data for densities of $\mathrm{NaNO}_{3}$ solutions at $293 \mathrm{~K}$ were $0.1 \%$ higher than the data reported by Weast (1985), and on average $0.26 \%$ higher than those of Isono (1984). Mahiuddin and Ismail (1996) provided least-square fitted parameter values for the density equation:

$$
\rho=a_{1}-b_{1}(T-273.15)
$$

where $\rho$ is density, and parameters $a_{1}$ and $b_{1}$ are concentration dependent, see Table 1 . The previous investigators did not give the parameters $a_{1}$ and $b_{1}$ as continuous functions of concentration. Because the thermophysical properties of $\mathrm{NaNO}_{3}$ solutions need to be represented with correlations suitable for implementation into the numerical simulator TOUGH2 (Pruess, 1991), we fitted parameters $a_{1}$ and $b_{1}$ as concentration-dependent functions using Microsoft Excel software. Since TOUGH2 uses mass fraction as a 
primary variable, we converted molality $(\mathrm{m}, \mathrm{mol} / \mathrm{kg})$ to mass fraction $(\mathrm{X})$ of $\mathrm{NaNO}_{3}$ in the aqueous phase by

$$
\mathrm{X}=\frac{\mathrm{mw}}{1000+\mathrm{mw}}
$$

where $\mathrm{w}=84.99471$ is the molecular weight of $\mathrm{NaNO}_{3}$. The corresponding mass fraction values are given in the second column of Table 1. Different orders of polynomial functions were fitted for parameters $a_{1}$ and $b_{1}$ based on data in Table 1 . The fitted curves are presented in Figures A.1 and A.2 of Appendix A. We chose a second-order polynomial for parameter $\mathrm{a}_{1}$, and a fifth-order polynomial for parameter $\mathrm{b}_{1}$ :

$$
\begin{aligned}
& a_{1}=421.37 X^{2}+629.7 X+1012.6 \\
& b_{1}=-168.16 X^{5}+206.79 X^{4}-89.845 X^{3}+17.308 X^{2}-0.6854 X+0.4789
\end{aligned}
$$

Table 1. List of parameters $a_{1}$ and $b_{1}$ in Equation (1) given by Mahiuddin and Ismail (1996).

\begin{tabular}{|l|l|l|l|l|}
\hline $\mathrm{m}(\mathrm{mol} / \mathrm{kg})$ & mass fraction, $\mathrm{X}$ & $\begin{array}{l}\text { Temperature range }(\mathrm{K}) \\
\text { /data points }\end{array}$ & $\mathrm{a}_{1}\left(\mathrm{~kg} \mathrm{~m}^{-3}\right)$ & $\mathrm{b}_{1}\left(\mathrm{~kg} \mathrm{~m}^{-3} \mathrm{~K}^{-1}\right)$ \\
\hline 0.1113 & 0.009371 & $328.8-293.6 / 11$ & 1018.5 & 0.4755 \\
0.5212 & 0.04242 & $326.5-293.3 / 12$ & 1040.1 & 0.4726 \\
1.0532 & 0.082162 & $328.5-295.7 / 12$ & 1067.4 & 0.4955 \\
1.8119 & 0.13345 & $325.2-295.6 / 11$ & 1103.8 & 0.5421 \\
2.5441 & 0.177791 & $328.1-300.5 / 12$ & 1139.2 & 0.5886 \\
3.3185 & 0.220002 & $325.6-300.7 / 11$ & 1171.1 & 0.5990 \\
4.3956 & 0.271987 & $324.1-299.0 / 11$ & 1213.6 & 0.6252 \\
5.3402 & 0.312189 & $328.6-301.4 / 12$ & 1250.2 & 0.6986 \\
6.2532 & 0.347041 & $329.8-302.5 / 12$ & 1282.6 & 0.7478 \\
7.3990 & 0.38608 & $328.3-301.2 / 12$ & 1317.5 & 0.7419 \\
8.3060 & 0.413822 & $327.5-298 / 12$ & 1348.4 & 0.8290 \\
9.8626 & 0.45601 & $327.6-301.1 / 12$ & 1385.8 & 0.7572 \\
\hline
\end{tabular}


Figure 1 shows density of $\mathrm{NaNO}_{3}$ solutions as a function of mass fraction (Eq 1.) using concentration-dependent $a_{1}$ and $b_{1}$ calculated from Eqs. (3) and (4), together with those using $a_{1}$ and $b_{1}$ from Table 1 given by Mahiuddin and Ismail (1996). It demonstrates that the present fitted functions for $\mathrm{a}_{1}$ and $\mathrm{b}_{1}$ are satisfactory.

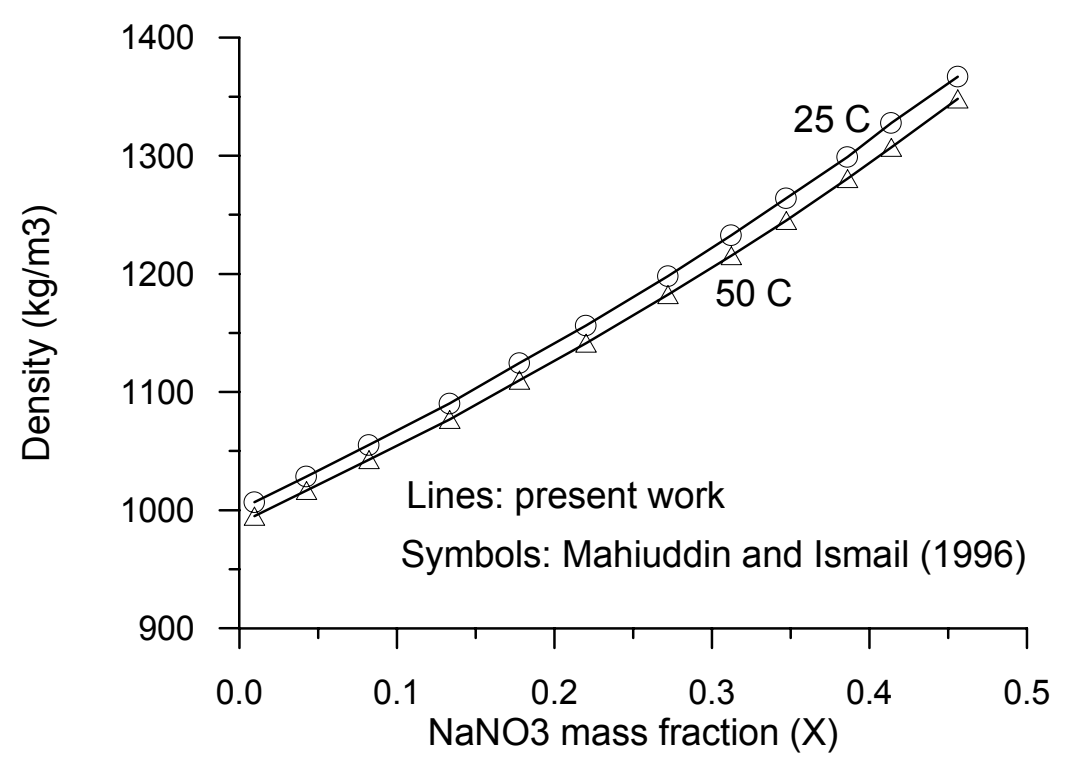

Figure 1. Density of $\mathrm{NaNO}_{3}$ solution as a function of mass fraction at 25 and $50{ }^{\circ} \mathrm{C}$ calculated from the fitted $a_{1}$ and $b_{1}$, together with those from $a_{1}$ and $b_{1}$ given by Mahiuddin and Ismail (1996).

\subsection{Viscosity}

The fitted temperature and concentration dependence of viscosity $(\mu)$ is also based on the measured data reported by Mahiuddin and Ismail (1996). Their measured viscosity values are in good agreement with data reported by Weast (1985) and Isono (1984). They used the following Vogel-Tammann-Fulcher equation, which has often been applied to viscosity, 


$$
\mu(\mathrm{Pa} \mathrm{s})=10^{-9} \mathrm{~A} \sqrt{\mathrm{T}} \exp \left[\left(\mathrm{B} /\left(\mathrm{T}-\mathrm{T}_{0}\right)\right]\right.
$$

where $\mathrm{A}, \mathrm{B}$, and $\mathrm{T}_{0}$ are parameters that are functions of the salt concentration. Mahiuddin and Ismail (1996) have provided the values of A, B, and $\mathrm{T}_{0}$ for each concentration point. In the present study, we fitted $\mathrm{A}, \mathrm{B}$, and $\mathrm{T}_{0}$, as polynomial functions of mass fraction $\mathrm{X}$, in a similar manner as for density. These fitted curves are presented in Figures A.3, A.4, and A.5. We chose a second-order polynomial for parameter A, a sixth-order for B, and a second-order for $\mathrm{T}_{0}$ :

$$
\begin{gathered}
\mathrm{A}=4219.6 \mathrm{X}^{2}+2995.2 \mathrm{X}+991.72 \\
\mathrm{~B}=300834 \mathrm{X}^{6}-525458 \mathrm{X}^{5}+348368 \mathrm{X}^{4}-106051 \mathrm{X}^{3}+14531 \mathrm{X}^{2}-967.34 \mathrm{X}+644.92 \\
\mathrm{~T}_{0}=29.088 \mathrm{X}^{2}+15.881 \mathrm{X}+134.68
\end{gathered}
$$

Figure 2 shows the computed values of viscosity of $\mathrm{NaNO}_{3}$ solutions as a function of mass fraction at three different temperatures, together with the measured data given by Mahiuddin and Ismail (1996). The computed viscosity values from the fitted functions are very close to the measured data. 


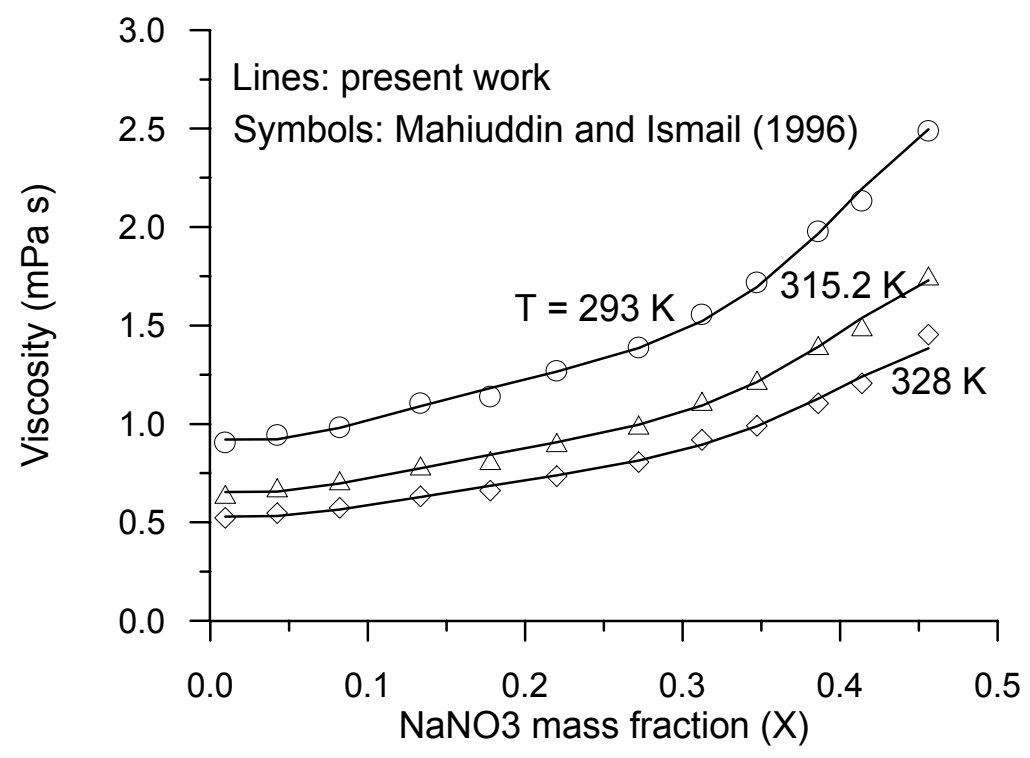

Figure 2. Computed viscosity values of $\mathrm{NaNO}_{3}$ solutions as a function of mass fraction at temperatures of $293,315.2$, and $328 \mathrm{~K}$, together with measured data given by Mahiuddin and Ismail (1996).

\subsection{Solubility}

The solubility data were taken from Apelblat and Korin (1998, Table 2). The original measured solubility data were reported in terms of moles per $\mathrm{kg} \mathrm{H}_{2} \mathrm{O}$. We converted this unit to the mass fraction. The fitted curve for solubility is presented in Figure A.6 of Appendix A. The fitted solubility (in mass fraction X) as a function of temperature ( $\mathrm{T}$ in degrees kelvin) is

$$
\mathrm{X}=0.0022 \mathrm{~T}-0.1757
$$




\subsection{Vapor pressure}

Apelblat and Korin (1998) also presented experimental data for temperature dependence of vapor pressure at $\mathrm{NaNO}_{3}$ saturated condition. A fitted curve of vapor pressure as a function of temperature is presented in Figure A.7 of Appendix A. The fitted function is

$$
\mathrm{P}_{\mathrm{s}}=0.0038 \mathrm{~T}^{2}-2.1085 \mathrm{~T}+293.76
$$

where $\mathrm{P}_{\mathrm{s}}$ is the vapor pressure at $\mathrm{NaNO}_{3}$ saturated condition. There is no vapor pressure data available for $\mathrm{NaNO}_{3}$ concentration intermediate between pure water and fully saturated conditions. For convenience, we here define a saturation index as, $S=X / X_{s}$, where $\mathrm{X}_{\mathrm{s}}$ is $\mathrm{NaNO}_{3}$ mass fraction at saturated condition and $\mathrm{X}$ is mass fraction at any concentration (for pure water, $S=0$; for fully saturated condition, $S=1$ ). Then, we estimate the vapor pressure at any $\mathrm{NaNO}_{3}$ concentration by linear interpolation

$$
\mathrm{P}=\mathrm{P}_{0}(1-\mathrm{S})+\mathrm{SP}_{\mathrm{S}}
$$

where $\mathrm{P}_{0}$ is the vapor pressure of pure water.

Note that measured data for density, viscosity, and vapor pressure of $\mathrm{NaNO}_{3}$ solutions are not available beyond $50{ }^{\circ} \mathrm{C}$. The extrapolation of the fitted functions should 
be validated as measurements at higher temperatures become available. The same is true for vapor pressure at any concentration $(0<\mathrm{S}<1)$.

\section{Comparison of Thermophysical Properties of $\mathrm{NaNO}_{3}$ and $\mathrm{NaCl}$}

Thermophysical properties of multiphase mixtures of $\mathrm{H}_{2} \mathrm{O}-\mathrm{NaCl}$ have been extensively studied and are better understood than those of $\mathrm{H}_{2} \mathrm{O}-\mathrm{NaNO}_{3}$. Brine waters are commonly present in the subsurface such as geothermal reservoirs, deep aquifers, and salt water intrusion regions. The studies of thermophysical behavior of $\mathrm{NaCl}$ solutions provide a basis for those of $\mathrm{NaNO}_{3}$. Battistelli et al. (1997) presented mathematical functions of some thermophysical properties of multiphase mixtures of $\mathrm{H}_{2} \mathrm{O}-\mathrm{NaCl}$ using data from the literature. In the present work, the functional relationships of salinity and temperature dependent properties of $\mathrm{NaCl}$ solutions were calculated from the expressions presented by Battistelli et al (1997).

The density, viscosity, kinematic viscosity (ratio of viscosity over density), and vapor pressure vs. mass fraction for both $\mathrm{NaNO}_{3}$ and $\mathrm{NaCl}$ solutions are presented in Figures $3,4,5$, and 6 , respectively. Those same parameters vs. mole fraction are presented in Figures 7, 8, 9, and 10, respectively. Solubilities (in terms of mass fraction) of $\mathrm{NaCl}$ and $\mathrm{NaNO}_{3}$ vs. temperature are presented in Figure 11. For mathematical conversion between mass and mole fractions, we present their relationship in Appendix B. For the same mass fractions, densities of both $\mathrm{NaNO}_{3}$ and $\mathrm{NaCl}$ solutions are similar (Figure 3). Viscosities of $\mathrm{NaNO}_{3}$ solutions are lower than those of $\mathrm{NaCl}$ especially at lower temperatures (such as at $25^{\circ} \mathrm{C}$ ) and greater mass fractions (Figure 4). The 
kinematic viscosity of $\mathrm{NaNO}_{3}$ solutions is similar to that of $\mathrm{NaCl}$, for mass fractions less than 0.2 (Figure 5), but for greater mass fraction at lower temperatures $\mathrm{NaNO}_{3}$ solutions have somewhat lower kinematic viscosity, which means that mobility (mass flux for a given pressure gradient) of $\mathrm{NaNO}_{3}$ solutions is greater than that of $\mathrm{NaCl}$ solutions. Vapor pressure of $\mathrm{NaNO}_{3}$ solutions is greater than that of $\mathrm{NaCl}$ especially at greater mass fractions and at higher temperatures (Figure 6).

For the same mole fractions, the density of $\mathrm{NaNO}_{3}$ solutions is greater than that of $\mathrm{NaCl}$ (Figure 7) at same temperatures because the molecular weight of $\mathrm{NaNO}_{3}(84.995$ $\mathrm{g} / \mathrm{mol})$ is much greater than that of $\mathrm{NaCl}(58.448 \mathrm{~g} / \mathrm{mol})$. Viscosities of both solutions are similar (Figure 8), but at low temperatures $\left(25^{\circ} \mathrm{C}\right)$ and greater mole fractions $(>0.07)$ the viscosity of $\mathrm{NaCl}$ solutions is greater than that of $\mathrm{NaNO}_{3}$. The pattern of kinematic viscosity is similar to that of viscosity (Figure 9). At higher temperatures such as $90{ }^{\circ} \mathrm{C}$ both are similar. At low temperatures $\left(25^{\circ} \mathrm{C}\right)$ and greater mole fractions, kinematic viscosity of $\mathrm{NaNO}_{3}$ is lower than that of $\mathrm{NaCl}$. For mole fractions less than 0.07 , vapor pressures of both solutions are very close. For greater mole fractions, vapor pressure of $\mathrm{NaNO}_{3}$ solutions is greater than that of $\mathrm{NaCl}$.

The thermophysical properties of both solutions in terms of mass and mole fractions can be summarized as follows. Density of $\mathrm{NaCl}$ solutions versus mass fraction is similar to that of $\mathrm{NaNO}_{3}$ (Figure 3). Viscosity of $\mathrm{NaCl}$ versus mass fraction is quite different from that of $\mathrm{NaNO}_{3}$ (Figure 4). While viscosities of both solutions versus mole fraction are similar (Figure 8). This suggests that viscosity may depend on the chemical interaction among ions (the unit of chemical interaction is mole). Density versus mass fraction for both solutions is approximately linear. Density versus mole fraction is close 
to linear. Viscosity versus both mass and mole fractions is non-linear especially at high salt concentrations. The dependence of kinematic viscosity is very similar to that of viscosity, because the non-linear viscosity curves are changed little when including the approximately linear dependence on density. The $\mathrm{NaNO}_{3}$-data at $90{ }^{\circ} \mathrm{C}$ are extrapolations from fits to experimental data extending only to $50{ }^{\circ} \mathrm{C}$.

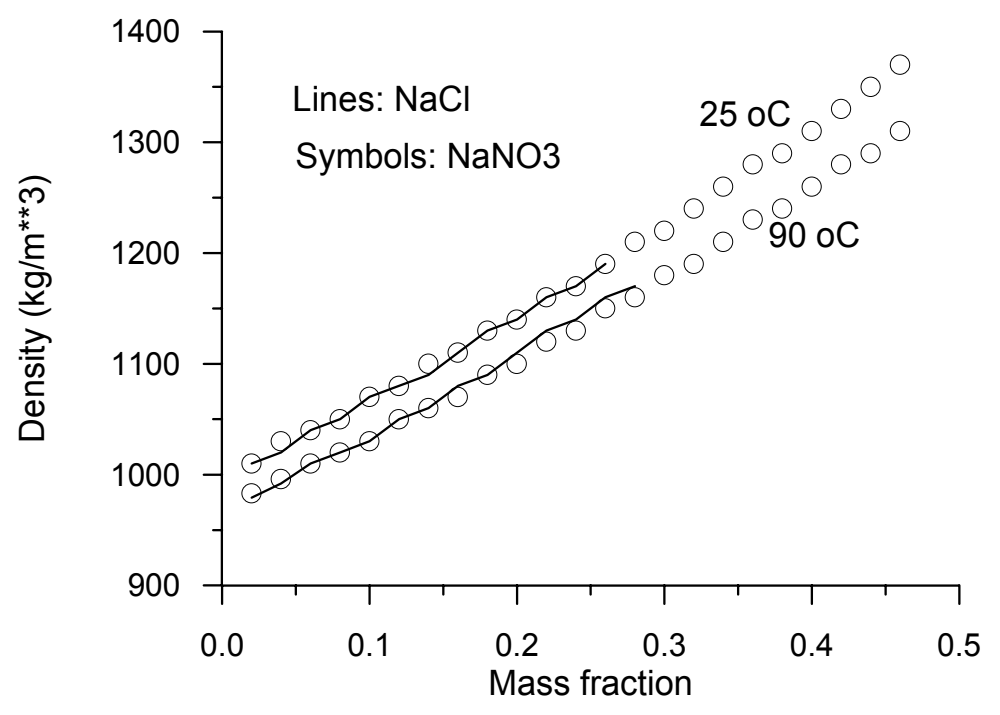

Figure 3. Densities of $\mathrm{NaCl}$ and $\mathrm{NaNO}_{3}$ solutions versus mass fraction at temperatures of 25 and $90{ }^{\circ} \mathrm{C}$ (at $90{ }^{\circ} \mathrm{C}$ solubility of $\mathrm{NaNO}_{3}$ can reach to 0.623 in mass fraction which is not plotted in this figure). 


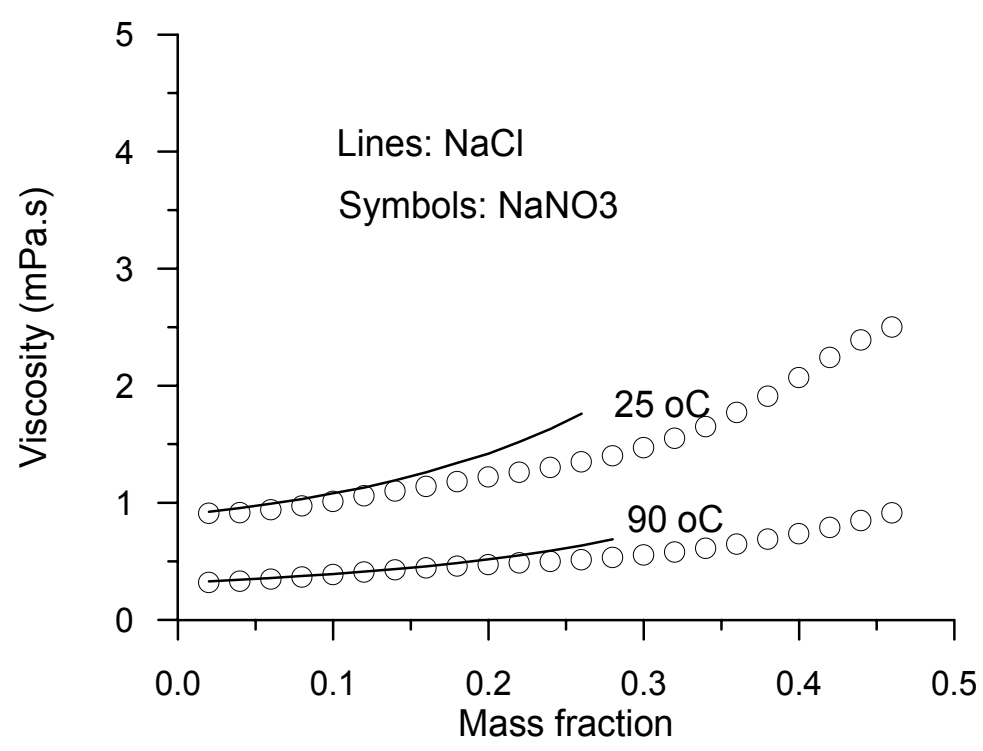

Figure 4. Viscosities of $\mathrm{NaCl}$ and $\mathrm{NaNO}_{3}$ solutions versus mass fraction at temperatures of 25 and $90{ }^{\circ} \mathrm{C}$.

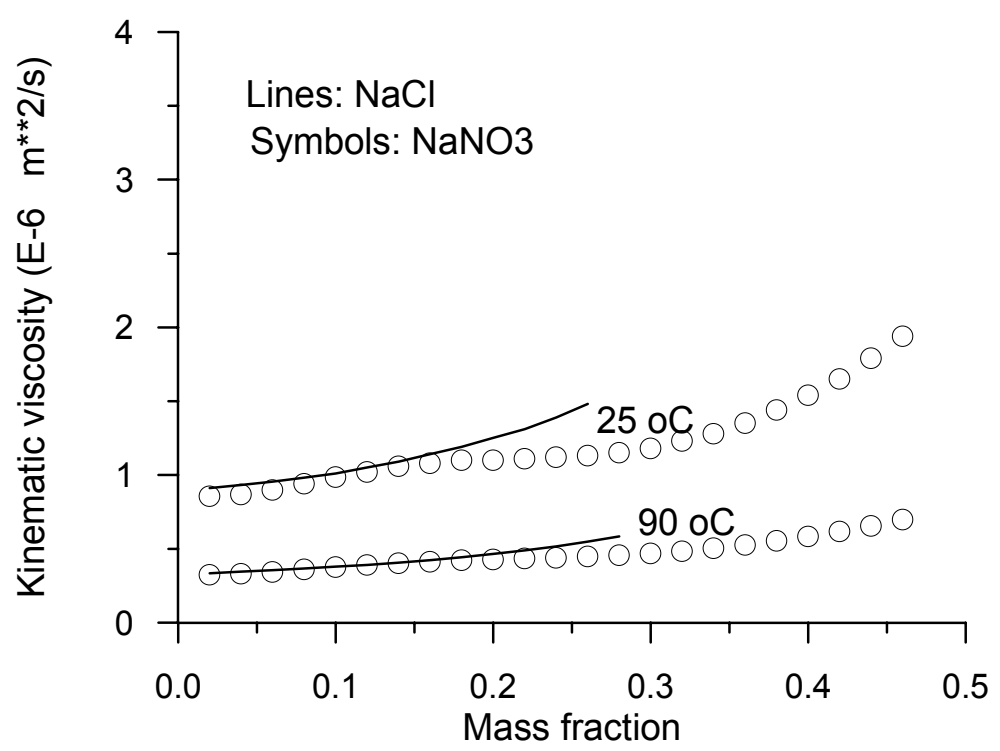

Figure 5. Kinematic viscosities of $\mathrm{NaCl}$ and $\mathrm{NaNO}_{3}$ solutions versus mass fraction at temperatures of 25 and $90^{\circ} \mathrm{C}$. 


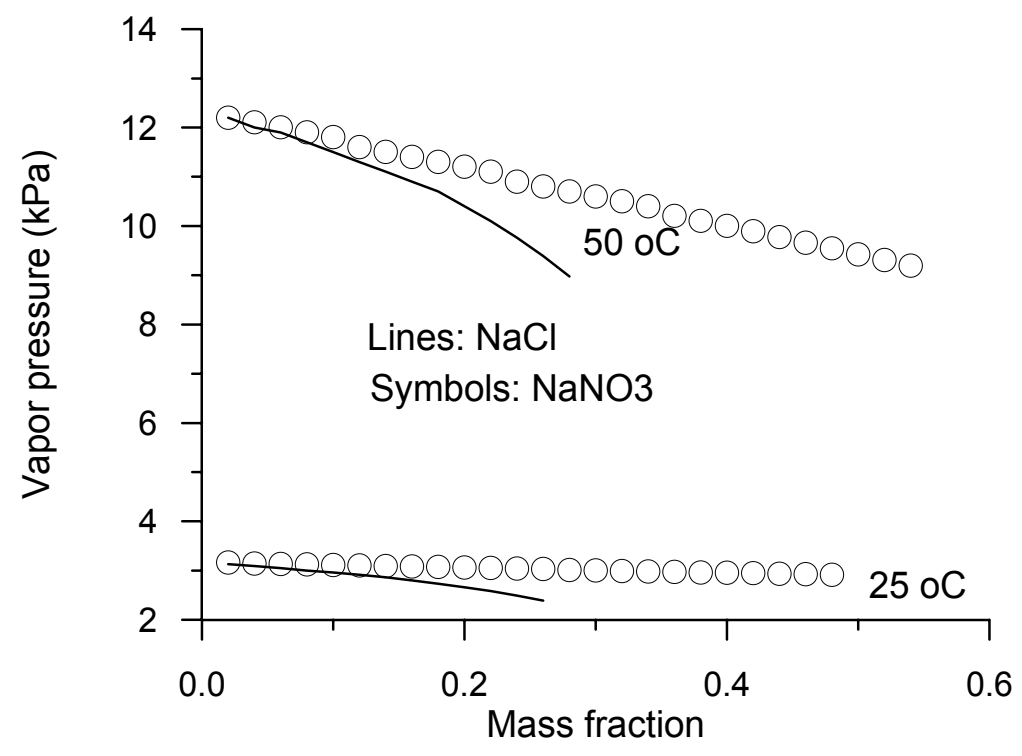

Figure 6. Vapor pressures of $\mathrm{NaCl}$ and $\mathrm{NaNO}_{3}$ solutions versus mass fraction at temperatures of 25 and $50{ }^{\circ} \mathrm{C}$.

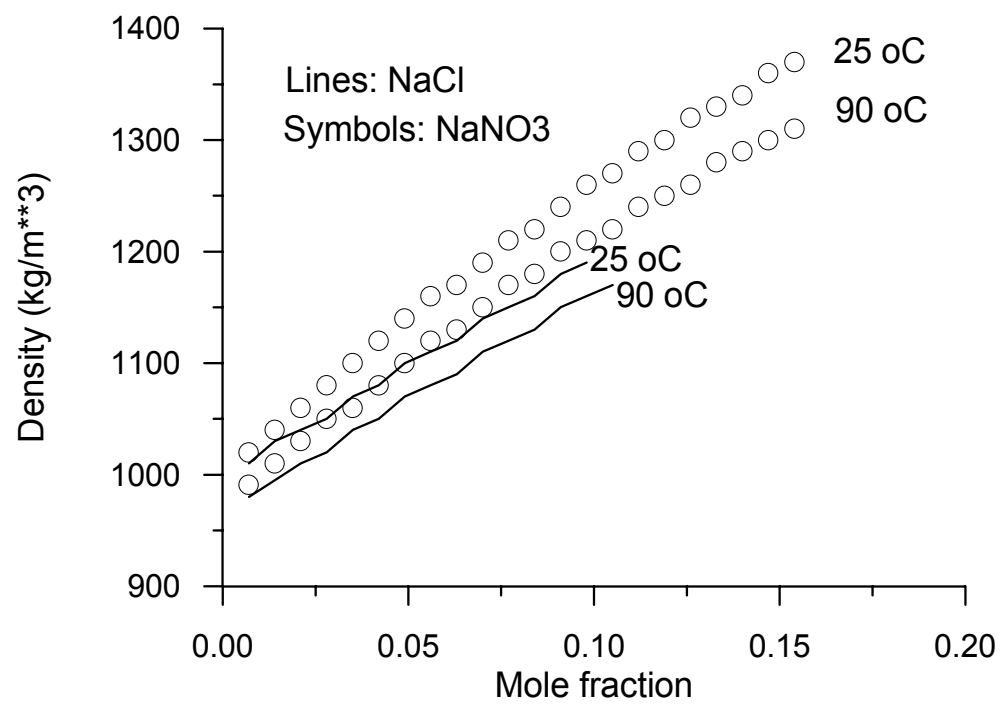

Figure 7. Densities of $\mathrm{NaCl}$ and $\mathrm{NaNO}_{3}$ solutions versus mole fraction at temperatures of 25 and $90{ }^{\circ} \mathrm{C}$ (at $90{ }^{\circ} \mathrm{C}$ solubility of $\mathrm{NaNO}_{3}$ can reach to 0.26 in mole fraction which is not plotted in this figure). 


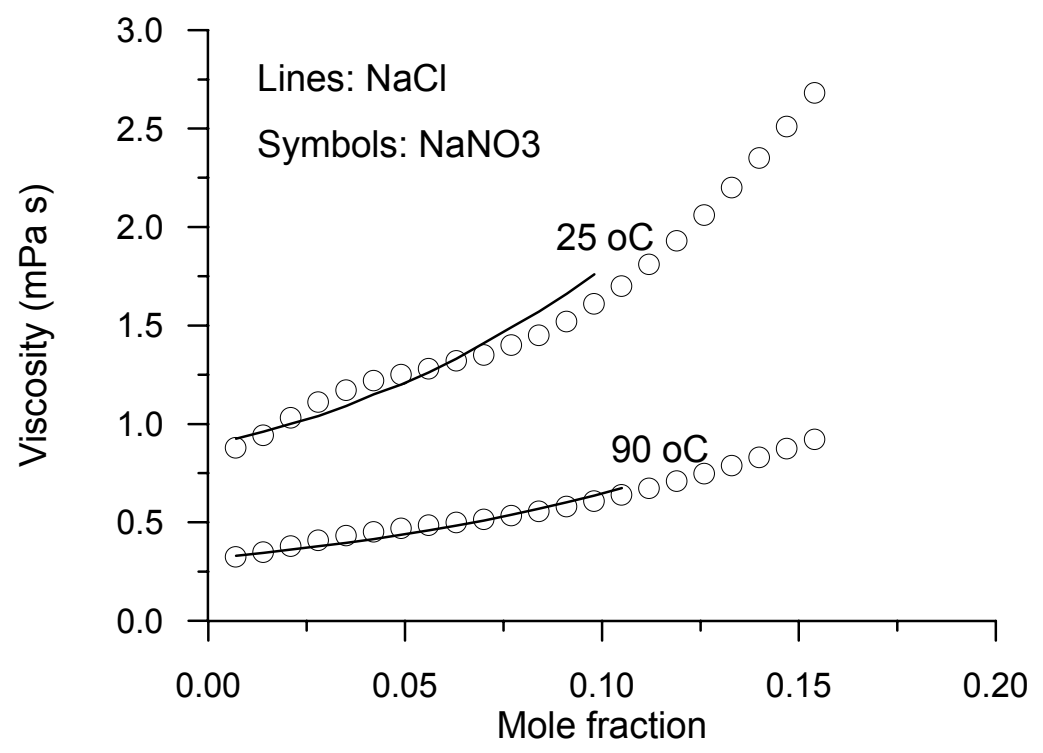

Figure 8. Viscosities of $\mathrm{NaCl}$ and $\mathrm{NaNO}_{3}$ solutions versus mole fraction at temperatures of 25 and $90{ }^{\circ} \mathrm{C}$.

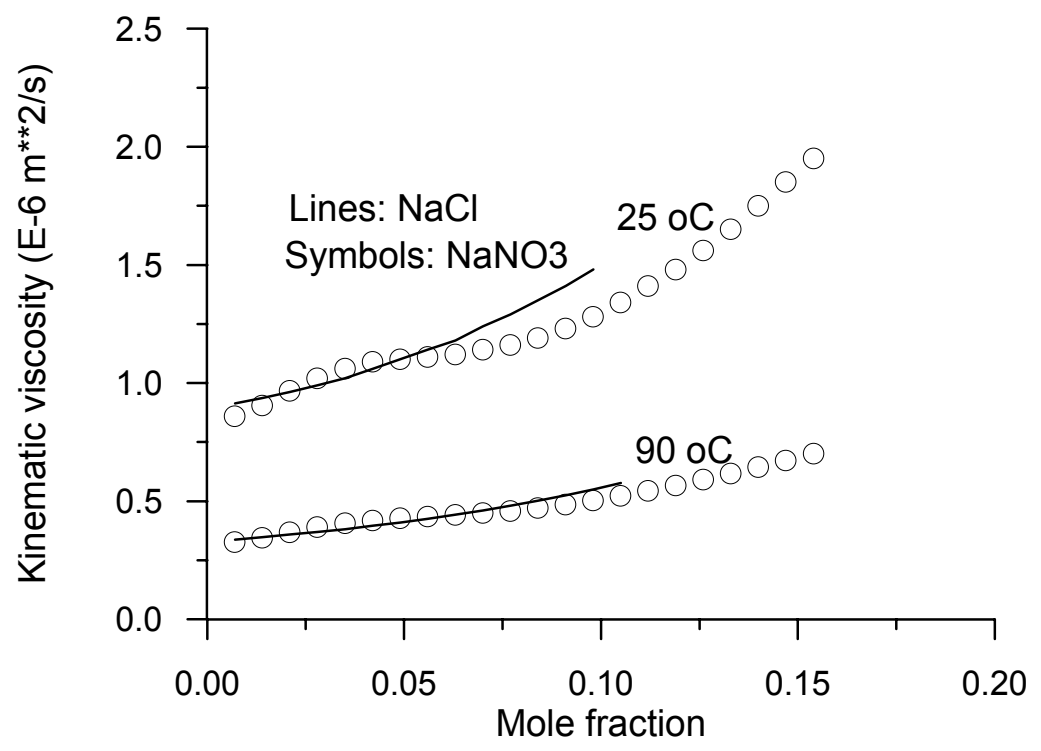

Figure 9. Kinematic viscosities of $\mathrm{NaCl}$ and $\mathrm{NaNO}_{3}$ solutions versus mole fraction at temperatures of 25 and $90{ }^{\circ} \mathrm{C}$. 


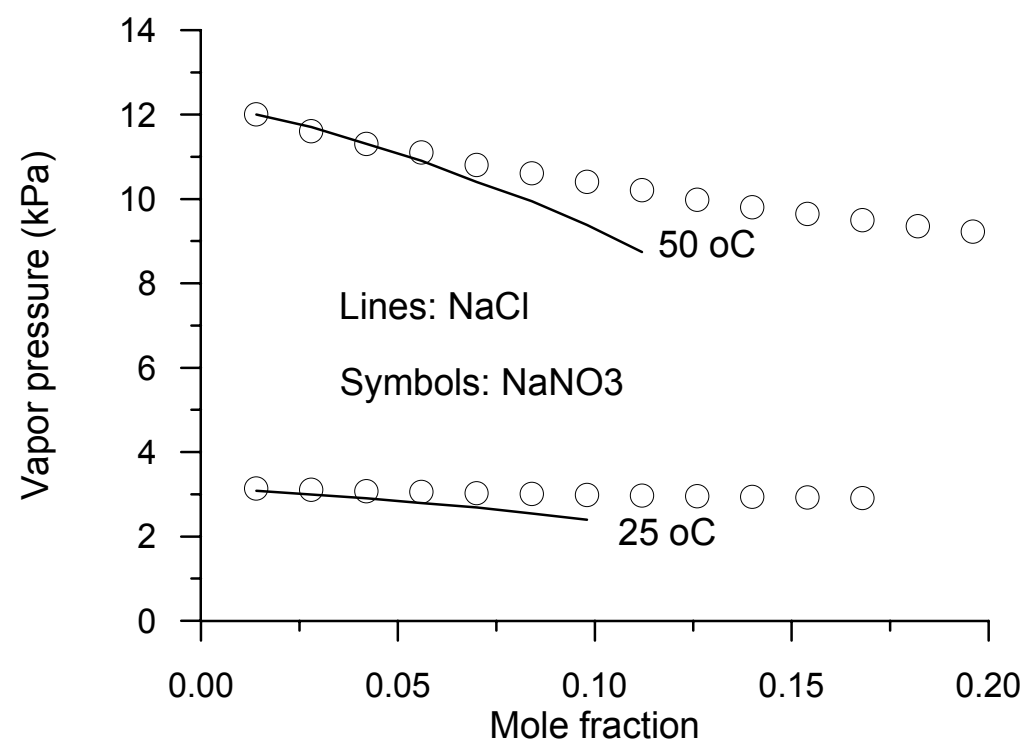

Figure 10. Vapor pressures of $\mathrm{NaCl}$ and $\mathrm{NaNO}_{3}$ solutions versus mole fraction at temperatures of 25 and $50{ }^{\circ} \mathrm{C}$.

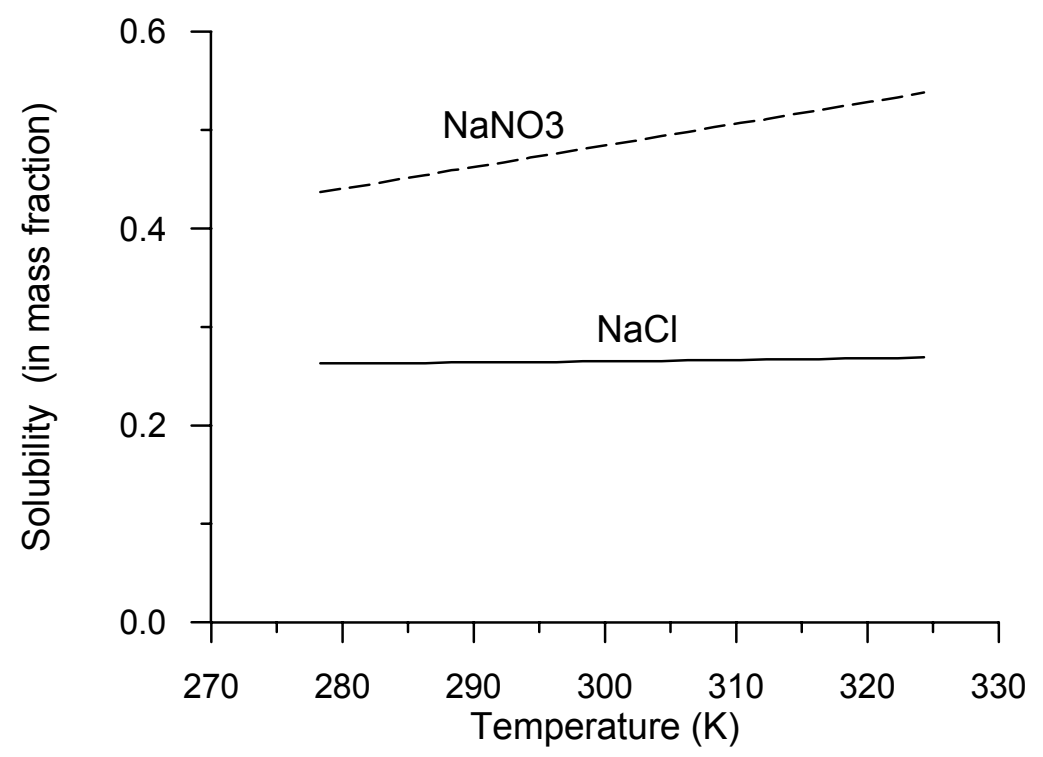

Figure 11. Solubility (in terms of mass fraction) of $\mathrm{NaCl}$ and $\mathrm{NaNO}_{3}$ vs. temperature. 


\section{Implementation}

Battistelli et al. (1997) presented a detailed study on thermophysical properties of multiphase mixture of $\mathrm{H}_{2} \mathrm{O}-\mathrm{NaCl}$. They implemented the functional relationships of salinity and temperature dependent thermophysical properties into an equation-of-state (EOS) module, EWASG, for TOUGH2 which is a multi-phase fluid and heat flow simulator (Pruess, 1991). The EWASG module is able to handle three-component mixtures of water, sodium chloride, and a slightly or moderately soluble non-condensible gas (NCG). The NCG can be chosen to be air, $\mathrm{CO}_{2}, \mathrm{CH}_{4}$, or $\mathrm{N}_{2}$. EWASG can describe liquid and gas phases, and includes precipitation and dissolution of solid salt. The dependence of density, viscosity, and vapor pressure of $\mathrm{NaCl}$ solutions on salt concentration is taken into account. In the present study as a starting point for implementing thermophysical properties of $\mathrm{NaNO}_{3}$ solutions, we adopted the equationof-state module EWASG for $\mathrm{NaCl}$ as a starting point for implementing thermophysical properties of $\mathrm{NaNO}_{3}$ solutions. Only four subroutines for density, viscosity, solubility, and vapor pressure were replaced by the expressions for $\mathrm{NaNO}_{3}$ as presented in Section 2. This equation-of-state module for $\mathrm{NaNO}_{3}$ preserves all capabilities of EWASG and was named EWASG_NaNO .

In the TOUGH2 simulator, transport of the mass components is considered to occur by advection and diffusion in liquid and gas phases. Heat transfer occurs by conduction, convection, and diffusion. It is assumed that the three phases (gas, liquid, and solid) are in local chemical and thermal equilibrium, and that no chemical reactions take place other than interphase mass transfer. The transport in geologic media is based on 
space discretization by means of integral finite differences (Narasimhan and Witherspoon, 1976). An implicit time-weighting scheme is used. The simulator is applicable to one-, two-, or three-dimensional geologic domains with heterogeneity. More details on the simulator are given by Pruess $(1987,1991)$ and Pruess et al. (1999).

\section{Simulations of Salinity-Driven Fluid Flow}

\subsection{Problem statement}

Weisbrod et al. (2000) performed a laboratory experiment to study the behavior of highly saline solutions in 2-D chambers. Their results showed that significant transport of water from pre-wetted sand into the highly saline $\mathrm{NaNO}_{3}$ solution plumes takes place in a matter of hours. If the sand is pre-saturated with the salt solution, the pure water is transferred into the saline environment. It is hypothesized that the major mechanism of moisture transfer is the migration of water vapor from regions with low salt concentration to the highly saline contaminated plume, due to vapor pressure lowering from salinity. As pointed out by Weisbrod et al. (2000), surface tension increase from higher salt concentration also may contribute to the migration towards the saline plume. The surface tension of saturated $\mathrm{NaCl}$ solutions at ambient conditions of $\mathrm{T}=20{ }^{\circ} \mathrm{C}, \mathrm{p}=1 \mathrm{~atm}$ is 0.081 $\mathrm{Nm}^{-1}$ (Adamson, 1990), approximately $11.4 \%$ larger than for pure water, which will give rise to somewhat stronger capillary suction pressures. This effect is not addressed in the present work. Here we use the simulation tools presented above to investigate thermophysical and hydrogeological conditions and parameters controlling this salinitydriven moisture transfer in unsaturated media. 
Vapor pressures of both $\mathrm{NaCl}$ and $\mathrm{NaNO}_{3}$ solutions decrease with salt concentration (Figures 6 and 10). This results in a vapor pressure gradient and consequent vapor diffusion from low to high salt concentration regions. Vapor then condenses in the high concentration regions and increases the liquid water saturation there. The relation of vapor diffusion to vapor pressure can be seen from the following two equations. The vapor diffusive flux can be expressed as

$$
\mathrm{F}_{\mathrm{g}}^{\mathrm{V}}=-\mathrm{D}_{\mathrm{g}}^{\mathrm{V}} \nabla \mathrm{C}_{\mathrm{g}}^{\mathrm{V}}
$$

where superscript $\mathrm{v}$ denotes vapor and subscript $\mathrm{g}$ denotes the gas phase, $\mathrm{F}$ is diffusive flux $\left(\mathrm{kg} \mathrm{m}^{-2} \mathrm{~s}^{-1}\right), \mathrm{D}$ is diffusion coefficient $\left(\mathrm{m}^{2} \mathrm{~s}^{-1}\right)$, and $\mathrm{C}$ is vapor concentration $\left(\mathrm{kg} \mathrm{m}^{-3}\right)$. According to the ideal gas law, we have

$$
\mathrm{C}_{\mathrm{g}}^{\mathrm{V}}=\mathrm{w} \frac{10^{-3}}{\mathrm{RT}} \mathrm{P}_{\mathrm{v}}
$$

where $\mathrm{w}$ is $\mathrm{H}_{2} \mathrm{O}$ molecular weight $\left(=18 \mathrm{~g} \mathrm{~mol}^{-1}\right), \mathrm{P}_{\mathrm{v}}$ is the vapor pressure $(\mathrm{Pa}), \mathrm{R}$ is the gas constant $\left(8.314 \mathrm{~J} \cdot \mathrm{mol}^{-1} \cdot \mathrm{K}^{-1}\right)$, and T is the absolute temperature. Diffusion coefficients of gaseous species in geologic media are calculated from

$$
\mathrm{D}_{\mathrm{g}}^{\mathrm{v}}=\tau_{\mathrm{g}} \phi \mathrm{S}_{\mathrm{g}} \mathrm{D}_{\mathrm{g}}^{\mathrm{v} 0}
$$


where $\mathrm{D}_{\mathrm{g}}^{\mathrm{v} 0}$ is the diffusion coefficient in pure gas phase, $\phi$ is porosity, $\mathrm{S}_{\mathrm{g}}$ is gas phase saturation, and $\tau_{\mathrm{g}}$ is tortuosity factor of the medium. $\tau_{\mathrm{g}}$ is related to $\phi$ and $\mathrm{S}_{\mathrm{g}}$, and has often been expressed by the model of the Millington and Quirk (1961)

$$
\tau_{\mathrm{g}}=\phi^{1 / 3} \mathrm{~S}_{\mathrm{g}}^{7 / 3}
$$

On the other hand, the aqueous phase flows from high to low water saturations due to capillary effect. This can be seen from Darcy's law excluding the gravity term (horizontal column)

$$
\mathrm{F}_{1}^{\mathrm{w}}=-\mathrm{k} \frac{\mathrm{k}_{\mathrm{rl}}}{\mu_{1}} \rho_{1} \nabla\left(\mathrm{P}_{\mathrm{r}}+\mathrm{P}_{\mathrm{c}}\right)
$$

where superscript $\mathrm{w}$ denotes water and subscript 1 denotes the liquid phase, $\mathrm{k}\left(\mathrm{m}^{2}\right)$ is the medium permeability, $\mathrm{k}_{\mathrm{rl}}$ is the relative permeability of liquid, $\rho$ is the phase density ( $\mathrm{kg}$ $\left.\mathrm{m}^{-3}\right), \mu$ is the phase viscosity $\left(\mathrm{kg} \mathrm{m}^{-1} \mathrm{~s}^{-1}\right), \mathrm{P}_{\mathrm{r}}$ is the reference pressure $(\mathrm{Pa})$, and $\mathrm{P}_{\mathrm{c}}(<0)$ is the capillary pressure $(\mathrm{Pa})$. By assuming $\mathrm{P}_{\mathrm{r}}$ to be constant, the pressure gradient comes only from capillary pressure. The higher the water saturation, the weaker (less negative) is the capillary pressure.

Vapor pressure depends not only on salinity, but also strongly on temperature. Obviously, heat transfer processes will play an important role in vapor diffusion. To investigate this coupled process driven by salinity gradients, we selected a onedimensional horizontal porous medium column for numerical experiments (see Figure 
12). The entire column has a uniform aqueous phase saturation of $S_{1}=0.3$, with a step change in salinity at $\mathrm{x}=0$ from $\mathrm{X}_{\mathrm{S}}=0.2$ for $\mathrm{x}<0$ to $\mathrm{X}_{\mathrm{S}}=0.0$ for $\mathrm{x}>0.0$. The column is infinite with a cross-sectional area of $1 \mathrm{~m}^{2}$. Hydrogeological parameters for the $1 \mathrm{D}$ problem were chosen representative of the Hanford formation (Khaleel and Freeman, 1995), which are listed in Table 2. We used a temperature of $50{ }^{\circ} \mathrm{C}$ that is representative of conditions near high heat load tanks at Hanford. A symmetric discretization scheme was used for both sides, with very fine gridding near $\mathrm{x}=0$. From the interface, we first use 10 constant grid blocks with a spacing of $1 \mathrm{~mm}$. Then we gradually increase the grid size; the grid has a total number of 62 blocks and extends from $\mathrm{x}=-120 \mathrm{~m}$ to $\mathrm{x}=120 \mathrm{~m}$ to obtain a system that is infinite acting over the time periods of interest in our simulations. Infinite volume was assigned for two end grid blocks to represent constant boundaries. Systematic simulation studies were performed to evaluate the following conditions and parameters controlling the salinity-driven fluid flow: (1) heat conduction, (2) permeability, and (3) temperature. We mainly use spatial distribution of variables (temperature, water saturation, salt mass fraction, and vapor pressure) after 0.5 years to illustrate the results obtained. We also present some temporal evolution to give a general picture.

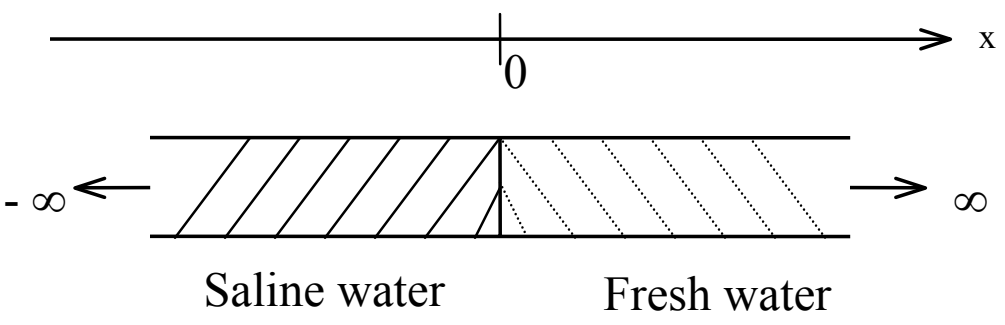

Figure 12. Schematic of 1-D unsaturated porous column used for numerical experiments. 
Table 2. List of hydrological parameters for the problem.

\begin{tabular}{ll}
\hline Parameter & Value \\
\hline porosity & 0.3586 \\
permeability $\left(\mathrm{m}^{2}\right)$ & $3.7 \times 10^{-13}$ \\
tortuosity & 0.25 \\
salt diffusion coefficient in water $\left(\mathrm{m}^{2} \mathrm{~s}^{-1}\right)$ & $10^{-9}$ \\
vapor diffusion coefficient $\left(\mathrm{m}^{2} \mathrm{~s}^{-1}\right)$ & $2.13 \times 10^{-5}$ \\
thermal conductivity $\left(\mathrm{Wm}^{-1} \mathrm{C}^{-1}\right)$ & 0.5 \\
grain specific heat $\left(\mathrm{J} \mathrm{kg}^{-1} \mathrm{C}^{-1}\right)$ & 920 \\
parameters & \\
$\lambda$ & 0.469 \\
$\mathrm{~S}_{\mathrm{lr}}$ & 0.0837 \\
$\mathrm{~S}_{\mathrm{ls}}$ & 1.0 \\
$\mathrm{P}_{0}(\mathrm{~Pa})$ & $9.394 \times 10^{-5}$ \\
\hline
\end{tabular}

${ }^{a}$ For relative permeability and capillary pressure functions [van Genuchten, 1980]:

\subsection{Non-isothermal effects}

To obtain better insight into the individual components of the salinity-driven fluid flow processes, we first suppressed liquid flow by increasing the residual water saturation $\left(\mathrm{S}_{\mathrm{lr}}=0.0837\right.$ in Table 2$)$ to 0.8837 . We simulated the 1-D problem under both nonisothermal and isothermal conditions. The non-isothermal simulation allows dynamical changes of temperature from an initial value of $50{ }^{\circ} \mathrm{C}$ due to latent heat effects from evaporation and condensation. In the isothermal simulation a constant temperature of 50 ${ }^{\circ} \mathrm{C}$ is maintained throughout. In these two simulations, we used a $\mathrm{NaCl}$ mass fraction of 0.2. The water saturations obtained from the two numerical experiments are essentially identical (Figure 13). The temperature in the non-isothermal simulation with $\mathrm{K}=0.5$ $\mathrm{Wm}^{-1} \mathrm{C}^{-1}$ always remains very close to $50{ }^{\circ} \mathrm{C}$ (Figure $14 \mathrm{a}$ ). At the saline water side, vapor pressure is lower due to salinity (Figure 14b). Vapor diffuses from the fresh water to the saline water side. Vapor condensation at the saline side increases water saturation. Evaporation at the fresh side decreases water saturation. 


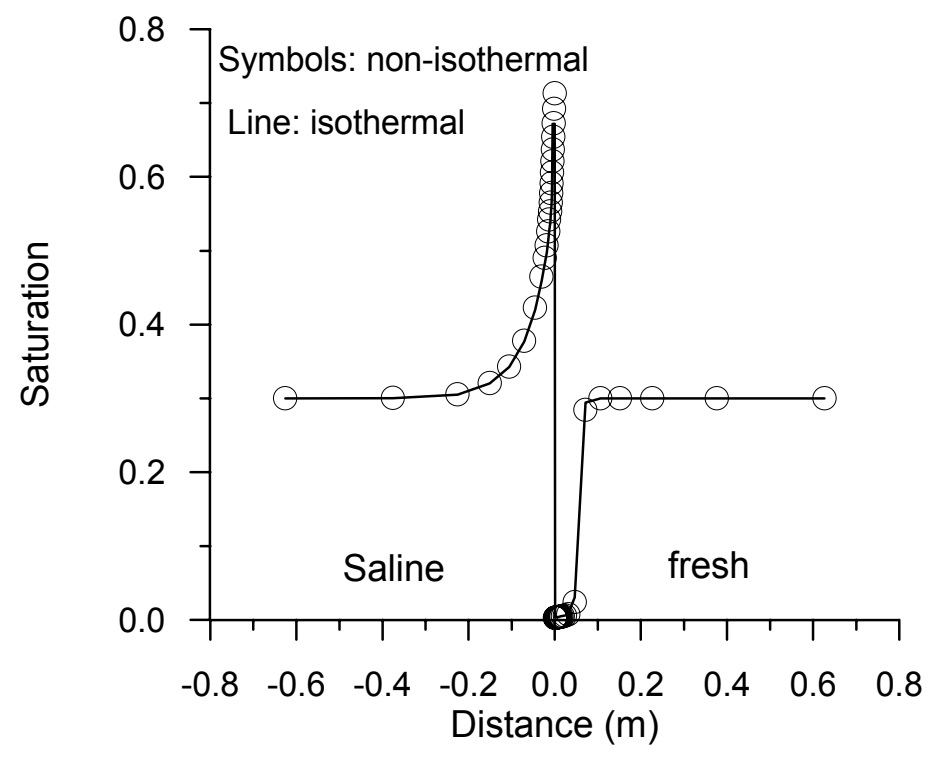

Figure 13. Water saturation after 0.5 year under non-isothermal and isothermal conditions (without considering liquid flow).

To examine the heat conduction effect, another simulation was performed with a heat conductivity of zero. Compared with the previous non-isothermal simulation using a heat conductivity of $0.5 \mathrm{Wm}^{-1} \mathrm{C}^{-1}$, temperature decreases at the fresh side due to evaporation and increases at the saline side due to condensation (Figure 14a). This demonstrates that heat conduction is able to rather completely compensate for the thermal effects from phase change, forcing the system to maintain a nearly uniform temperature. Heat conduction completely smears the evaporation and condensation effects on temperature. When heat conduction is neglected, the decrease in temperature at the fresh side results in a decrease in vapor pressure compared to the case with heat conduction (Figure 14b). At the interface between fresh and saline sides the vapor pressure gradient is then significantly lower compared to the case with heat conduction. Therefore, much less vapor then diffuses from the fresh to the saline side, and water saturation is only 
slightly changed from the initial state (Figure 15a). On the scale of Figure 15a the change in water saturation for the case of zero heat conductivity, is barely noticeable. On the enlarged scale in Figure 15b, it is seen that some vapor did diffuse from the fresh to the saline side, causing a very small increase in water saturation there. The simulation with zero conductivity indicates that heat conduction process plays a very important role in this salinity-driven vapor diffusion, maintaining the process at a nearly constant temperature.

We also simulated a case with irreducible water saturation restored to $\mathrm{S}_{\mathrm{lr}}=0.0837$ so that water is mobile. The temperature distribution obtained from the non-isothermal simulation with liquid flow also remains very close to the initial value of $50{ }^{\circ} \mathrm{C}$ at all times. Therefore, in all following simulations we use only isothermal conditions.

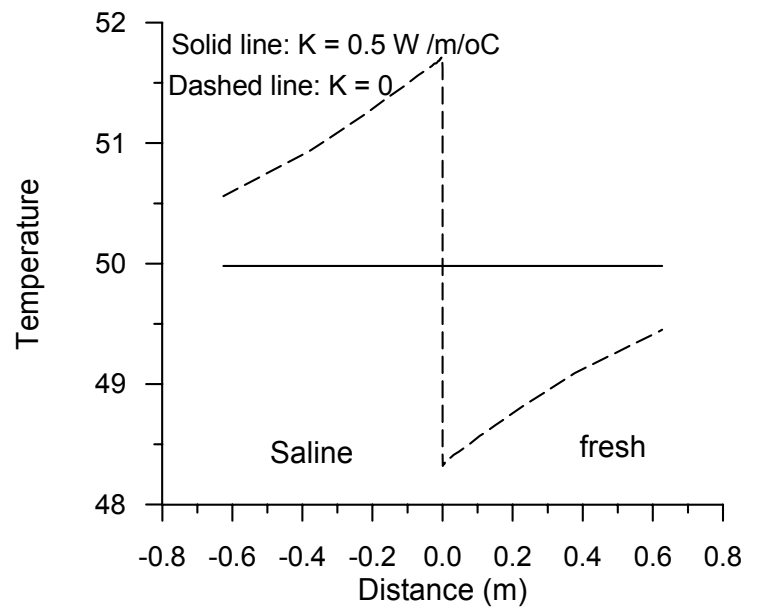

(a) Temperature

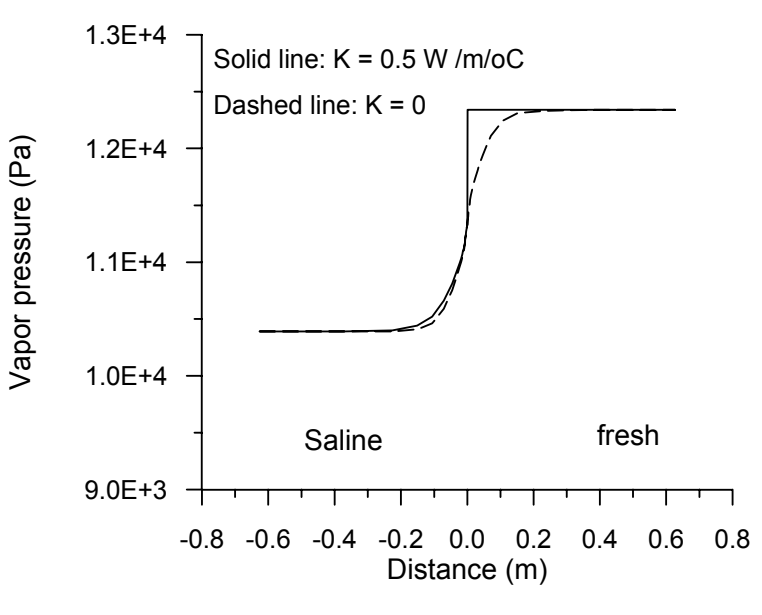

(b) Vapor pressure

Figure 14. Temperature and vapor pressure after 0.5 year for non-isothermal simulation using two different thermal conductivity values. 


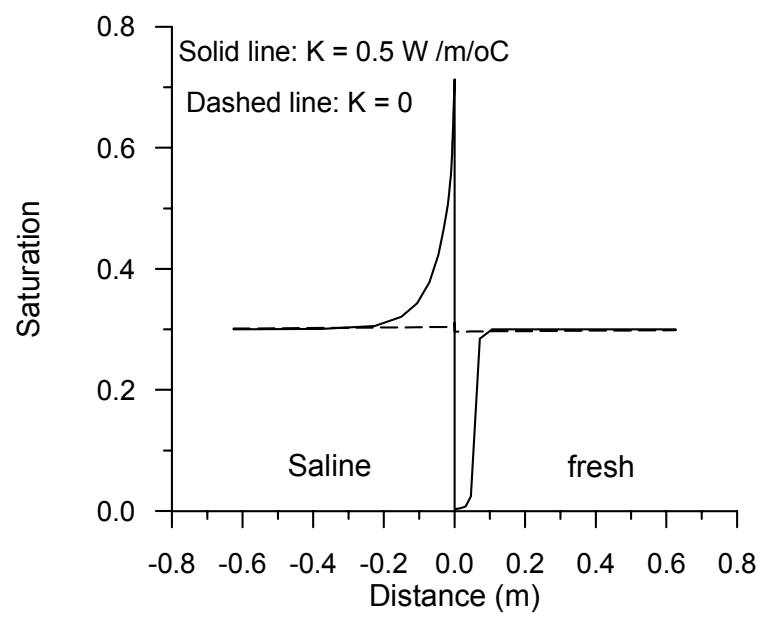

(a)

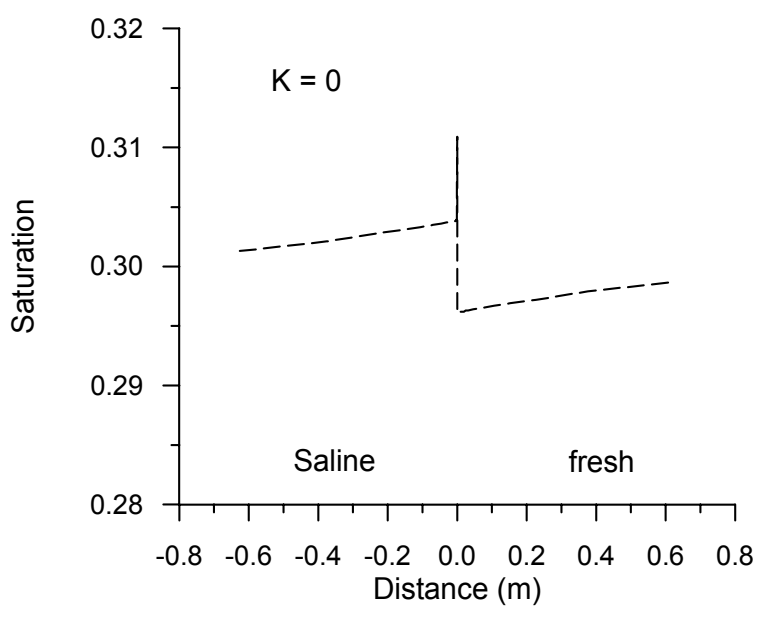

(b)

Figure 15. Water saturation after 0.5 years obtained with different thermal conductivities.

\subsection{Salinity driven fluid flow}

We used both $\mathrm{NaCl}$ and $\mathrm{NaNO}_{3}$ solutions with a mass fraction of 0.2 . Figure 16 shows water saturations from both salt solutions. Water saturations on the saline side obtained for immobile liquid are significantly increased due to moisture transport from vapor diffusion (Figure 16a). When allowing for liquid flow, water saturations are only slightly changed from the initial values (Figure 16b). This is because the liquid water flows back from the saline to the fresh side due to capillary effects. On the enlarged scale of Figure 17, it can be seen that water saturations on the saline side are slightly higher than on the fresh side. Figure 18 shows salt mass fraction after 0.5 year without and with liquid mobility. At the saline side close to the interface salt concentration has decreased from the initial value (0.2) due to condensation. For the case with liquid flow, at the fresh side close to the interface salt concentration is higher than the initial value $(0.0)$ because of capillary-driven flow towards the region with lower water saturation. 


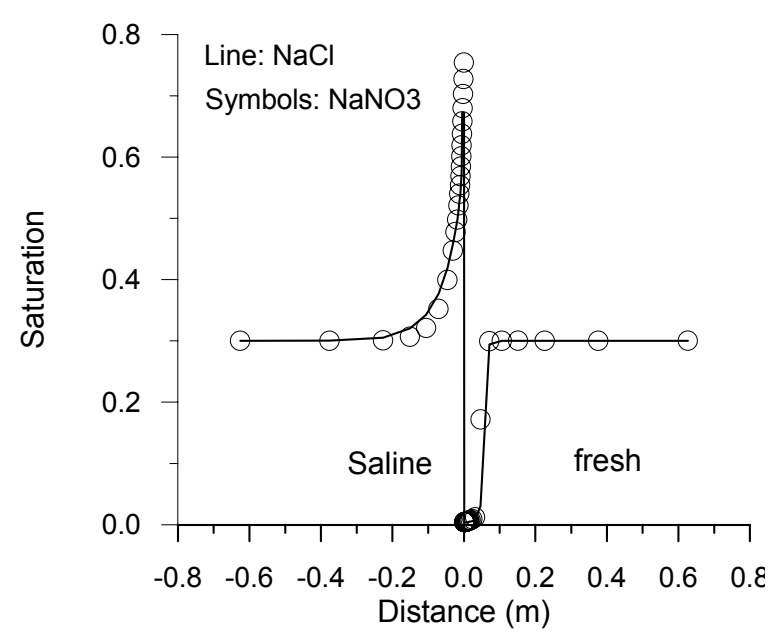

(a) Liquid immobile

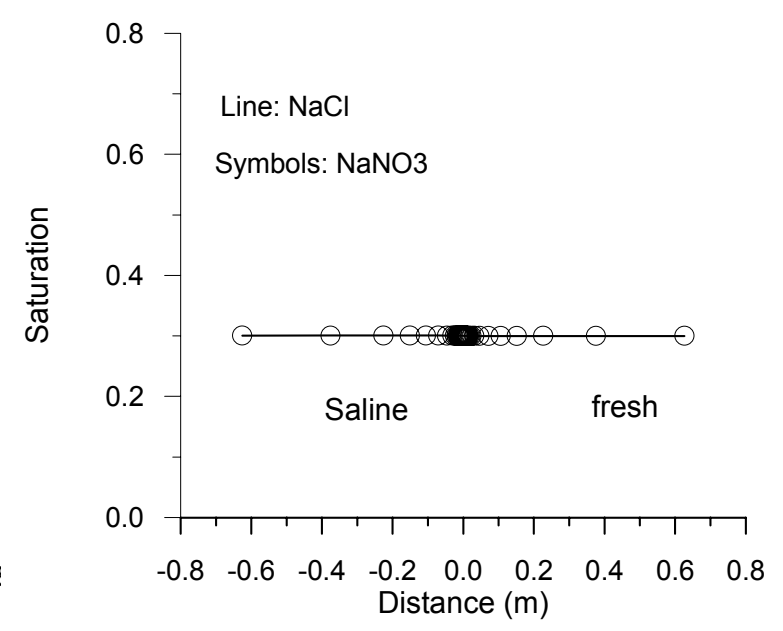

(b) Liquid mobile

Figure 16. Water saturations after $0.5 \mathrm{yr}$ without and with liquid flow.

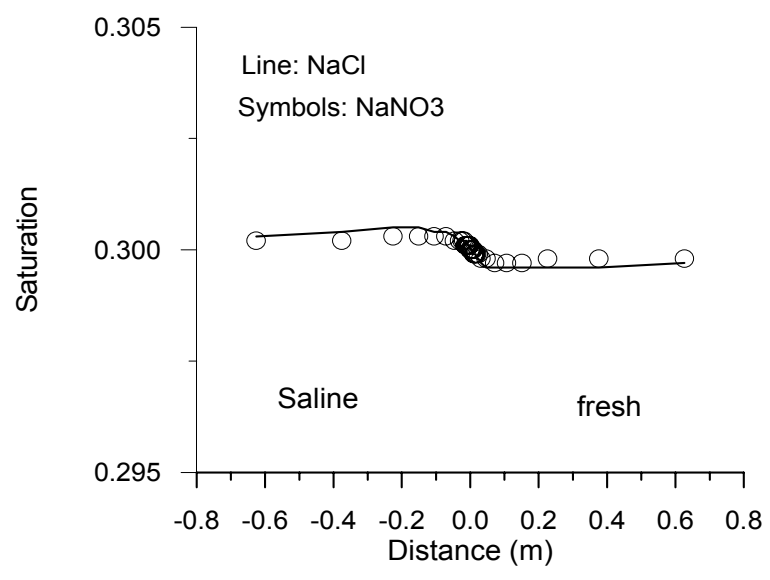

Figure 17. Water saturation after 0.5 year with liquid mobile (enlarged from Figure $16 \mathrm{~b}$ ) 


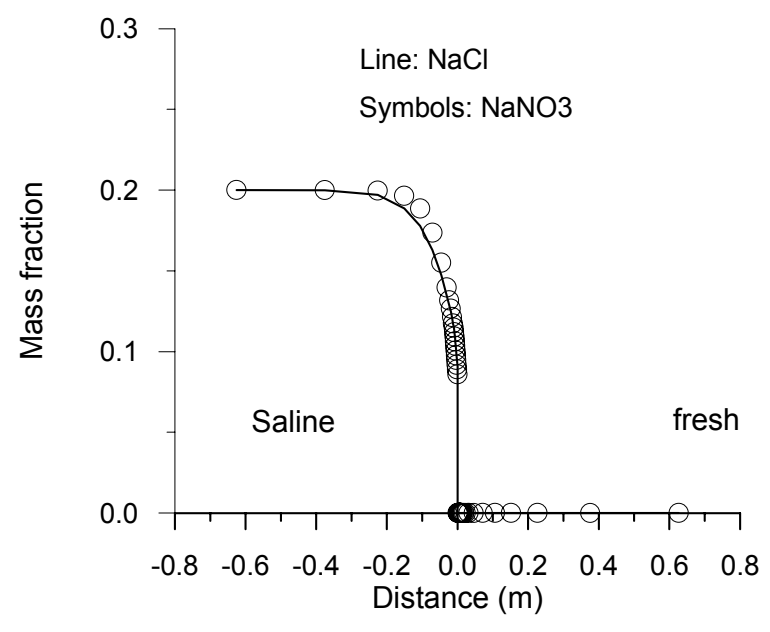

(a) Liquid immobile

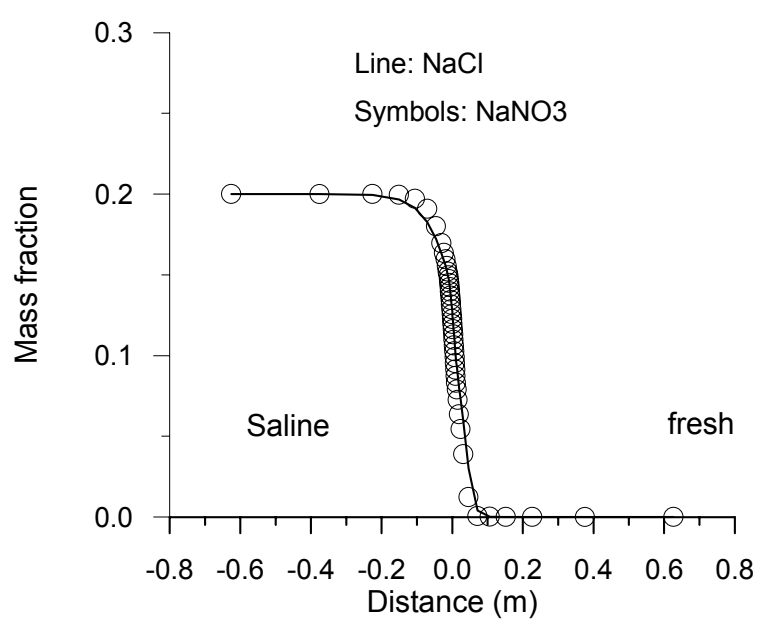

(b) Liquid mobile

Figure 18. Salt mass fraction after 0.5 year without and with liquid flow.

Since the molecular weight of $\mathrm{NaNO}_{3}$ is greater than that of $\mathrm{NaCl}$ (84.995 vs. $58.448 \mathrm{~g} / \mathrm{mol}$ ), we now use a mass fraction of 0.26673 for $\mathrm{NaNO}_{3}$ that corresponds to the same mole fraction $(0.071581)$ as 0.2 mass fraction for $\mathrm{NaCl}$. The resulting water saturation without considering liquid flow is presented in Figure 19. Water saturation obtained from $0.26672 \mathrm{NaNO}_{3}$ mass fraction is similar to that from the previous 0.2 mass fraction (compare Figure 19 to Figure 16a). Solubility of $\mathrm{NaNO}_{3}$ is much higher than that of $\mathrm{NaCl}$ (Figure 11). At $50{ }^{\circ} \mathrm{C}$, the solubility of $\mathrm{NaNO}_{3}$ is 0.53523 in mass fraction, while the solubility of $\mathrm{NaCl}$ is about 0.26 , close to the value (0.2) used in the previous simulations. For the saturated $\mathrm{NaNO}_{3}$ mass fraction of 0.53523 , the vapor pressure lowering effect is stronger than for the under-saturated mass fraction of 0.2 (Figure 20). 


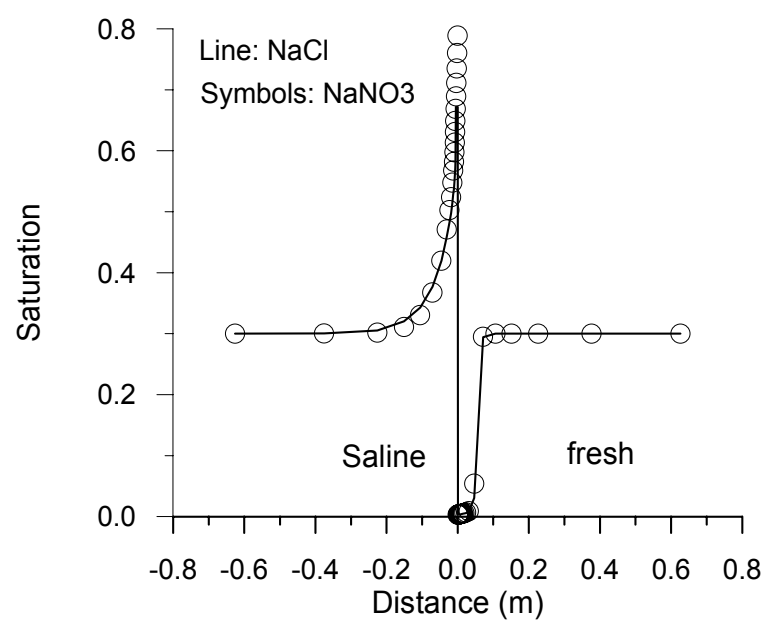

Figure 19. Water saturation after 0.5 year using a same mole fraction of $0.071581(\mathrm{NaCl}$ mass fraction 0.2 , and $\mathrm{NaNO}_{3} 0.26673$ ).

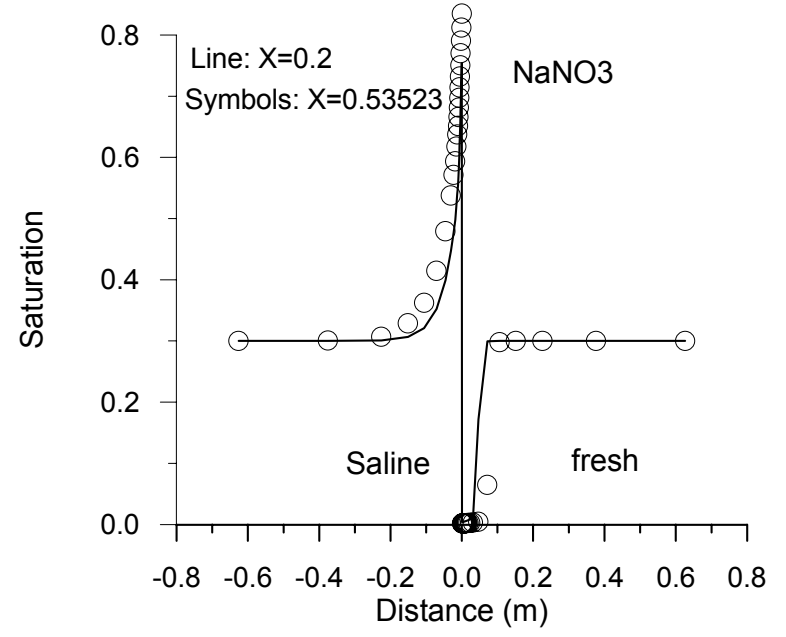

Figure 20. Water saturation obtained from $\mathrm{NaNO}_{3}$ mass fractions of 0.2 and 0.53523 .

\subsection{Sensitivity to permeability}

The vapor pressure lowing at the saline side draws vapor from the fresh to the saline side by diffusion. Simultaneously, the capillary force draws water from the elevated saturation on the saline to the fresh side. The migration of water in unsaturated media depends on capillary pressure and medium hydrological properties such as 
permeability. Capillary pressure is a function of water saturation and pore size distribution. For some types of porous media, such as sandstones and sedimentary formations, capillary pressure is inversely proportional to the square root of permeability (Leverett, 1941). Here we study two cases where permeability listed in Table 2 is decreased by 2 and 4 orders of magnitude. The capillary pressure parameter $\left(\mathrm{P}_{0}\right.$ in Table 2 ) is changed accordingly (increased by 1 and 2 orders of magnitude). The simulated water saturations for different cases are presented in Figure 21. Generally the changes in water saturation are larger for lower permeability. The decreased permeability reduces water mobility, but it increases the capillary pressure. The permeability effect is dominant. For the same mass fraction of 0.2 , the permeability effect for $\mathrm{NaCl}$ is more pronounced than that for $\mathrm{NaNO}_{3}$ (compare Figure 21a to b). When $\mathrm{NaNO}_{3}$ mass fraction is increased to the saturated level $(0.53523)$, the permeability effect is very strong (compare Figure 21d to b). 


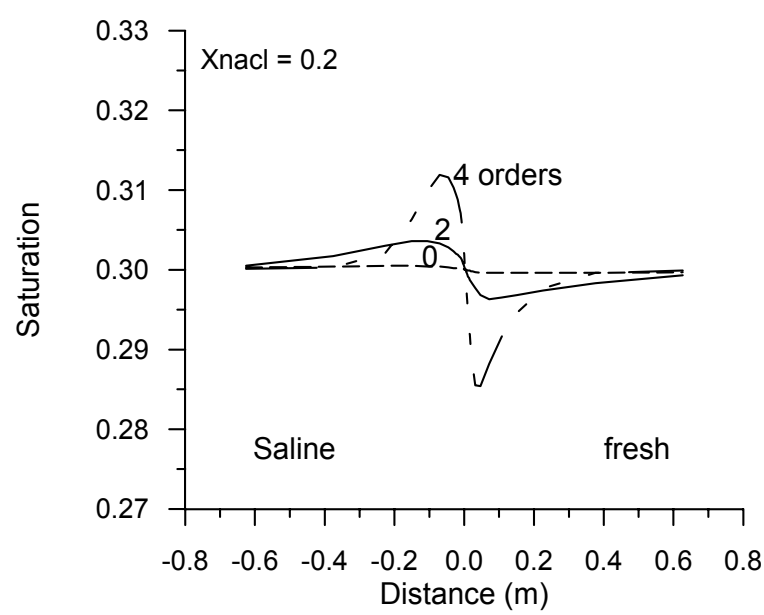

(a)

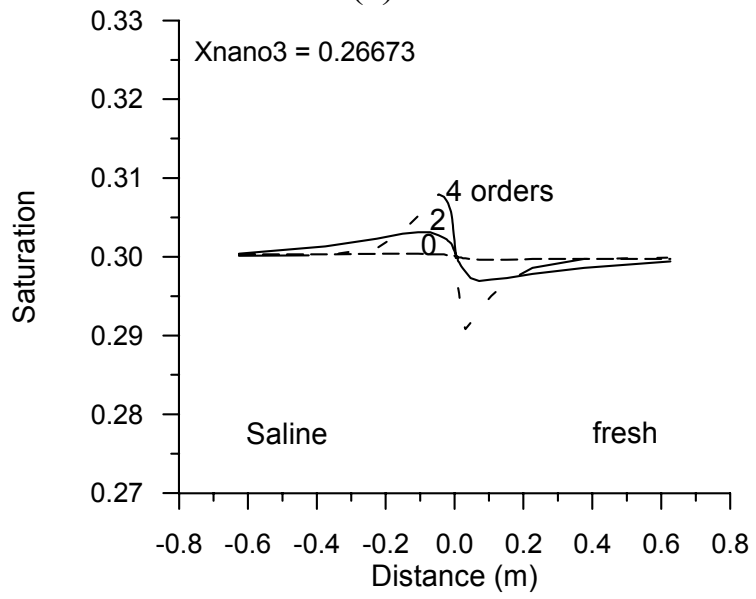

(c)

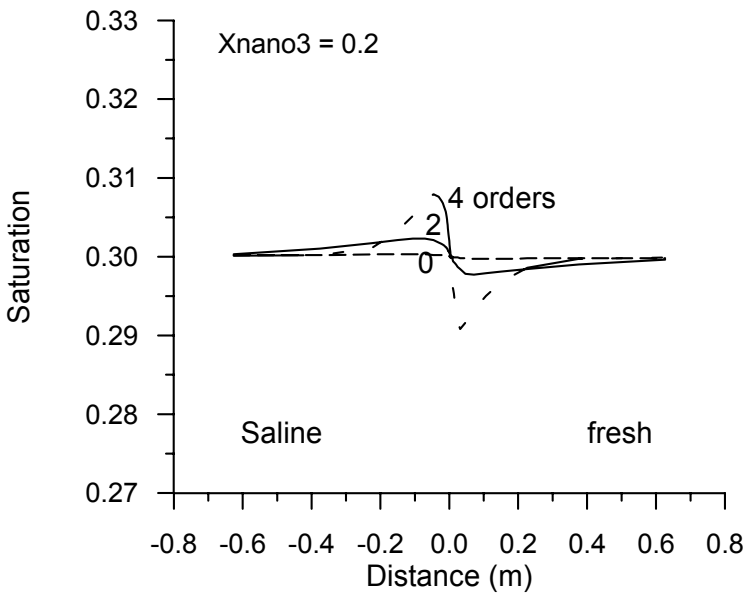

(b)

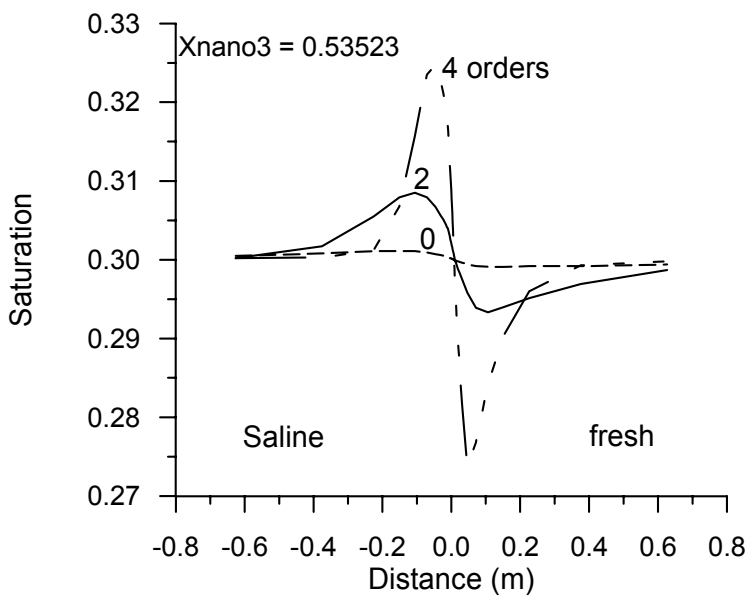

(d)

Figure 21. Water saturations obtained with permeability values decreased by 2 and 4 orders of magnitude (correspondingly capillary pressures increased by 1 order and two orders of magnitude).

In these simulations, tortuosity was held constant, but in reality it is likely to decrease with decreasing permeability. Since quantitative relationships between permeability and tortuosity are not available, we simply used two additional values of tortuosity 0.125 and 0.05 that are decreased from the value of 0.25 in Table 2 . Tortuosity 
simulations use a temperature of $50{ }^{\circ} \mathrm{C}$, a $\mathrm{NaCl}$ mass fraction of 0.2 , and a permeability value decreased by 4 orders of magnitude from the value in Table 2. A decrease in tortuosity results in a decrease in salinity driven vapor diffusion. Consequently, water saturation changes are reduced (Figure 22).

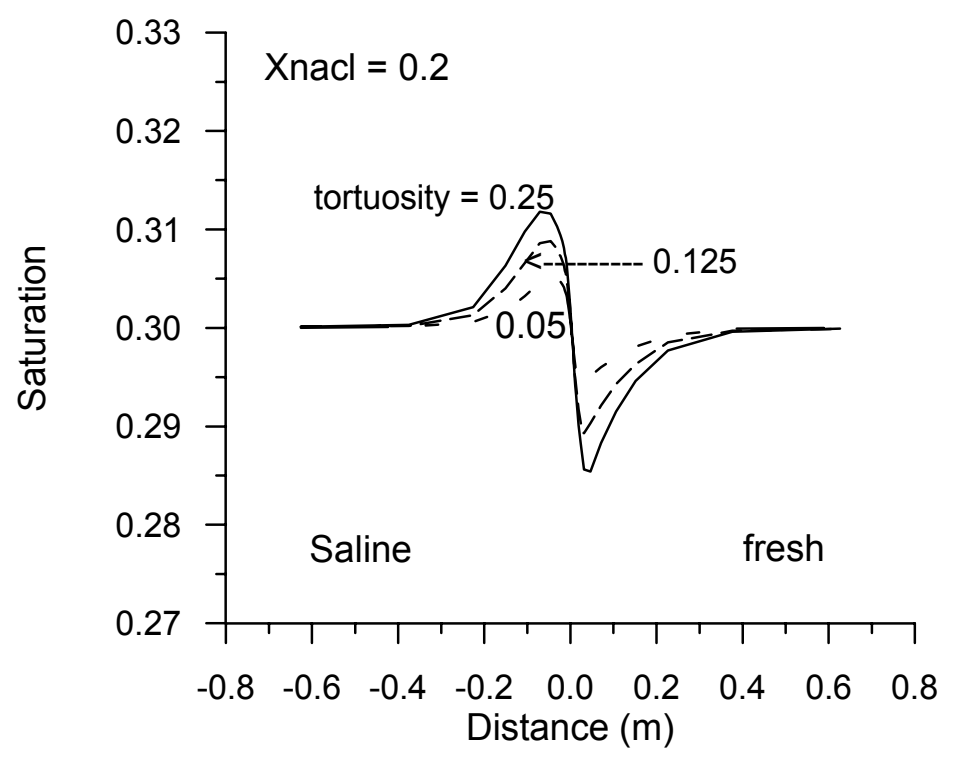

Figure 22. Water saturation obtained with different tortuosity values using a permeability value decreased by 4 orders of magnitude and a temperature $50{ }^{\circ} \mathrm{C}$.

\subsection{Sensitivity to temperature}

In addition to the salinity, vapor pressure also depends on temperature. To obtain further insight into the sensitivity of the salinity-driven fluid flow to temperature, we used (1) two additional temperatures, a lower $25^{\circ} \mathrm{C}$ and a higher $80{ }^{\circ} \mathrm{C}$, (2) both $\mathrm{NaCl}$ and $\mathrm{NaNO}_{3}$ solutions with a mass fraction of 0.2 , and (3) permeability values decreased by two and four orders of magnitude. We have mentioned before that measured data beyond $50{ }^{\circ} \mathrm{C}$ for vapor pressure, density, and viscosity of $\mathrm{NaNO}_{3}$ solutions are not available. We assumed that the extrapolations of the fitted function are valid. This may 
be justified due to the fact that the trend of $\mathrm{NaNO}_{3}$ vapor pressure curve is similar to that of $\mathrm{NaCl}$ (Figures 6 and 10) and measured data at higher temperatures for the latter are available. Results from temperature sensitivity simulations are presented in Figure 23. Generally the higher the temperature, the higher the difference of water saturations between the saline and fresh sides. This was expected because vapor pressures and vapor diffusive fluxes increase strongly with temperature. The lower the permeability, the sharper the variations in water saturation are (compare Figures $23 \mathrm{c}$ and $\mathrm{d}$, to a and b). It means that the propagation of this salinity-driven fluid flow is limited in areas of low permeability. At 20 and $50{ }^{\circ} \mathrm{C}$, the salinity driven fluid flow of $\mathrm{NaCl}$ solutions is more pronounced, but at $80{ }^{\circ} \mathrm{C}$ that of $\mathrm{NaNO}_{3}$ solutions is slightly more significant. 


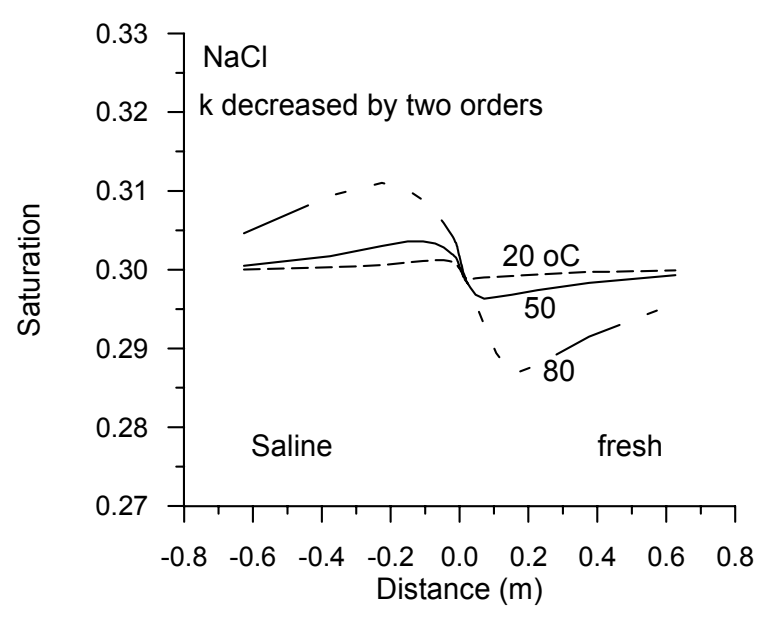

(a)

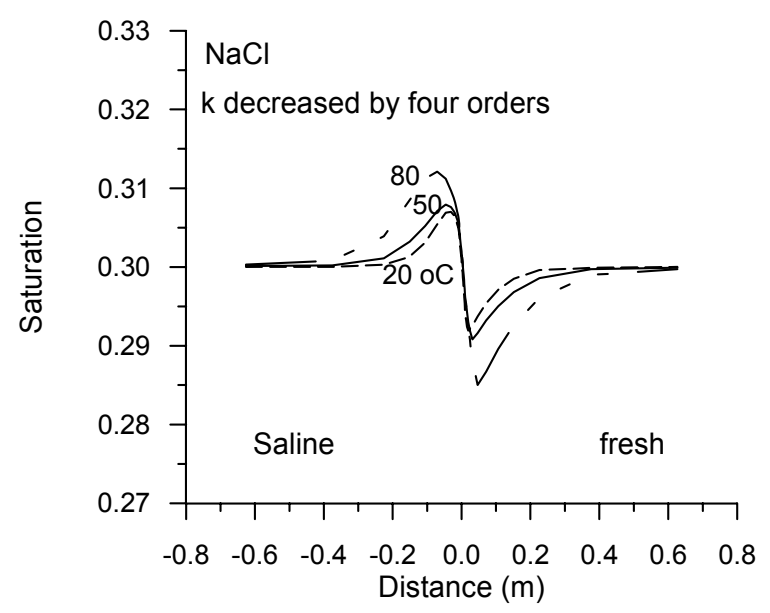

(c)

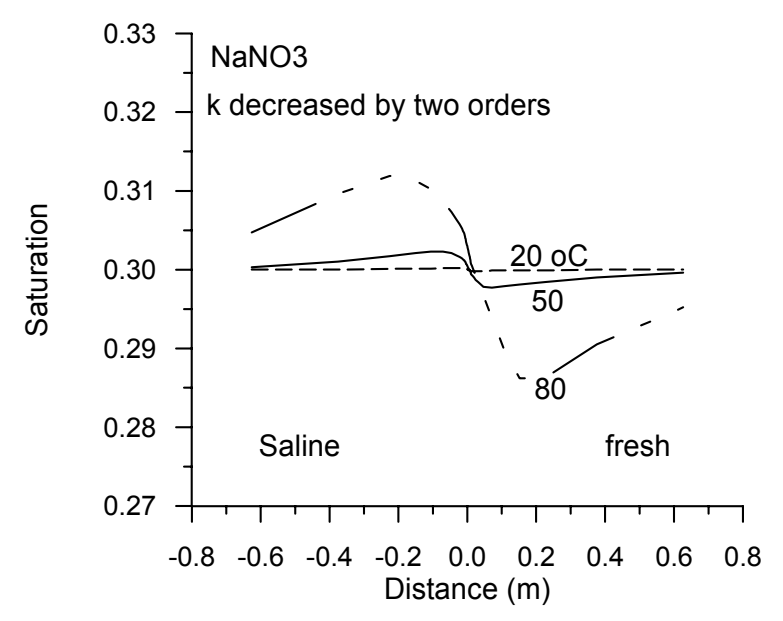

(b)

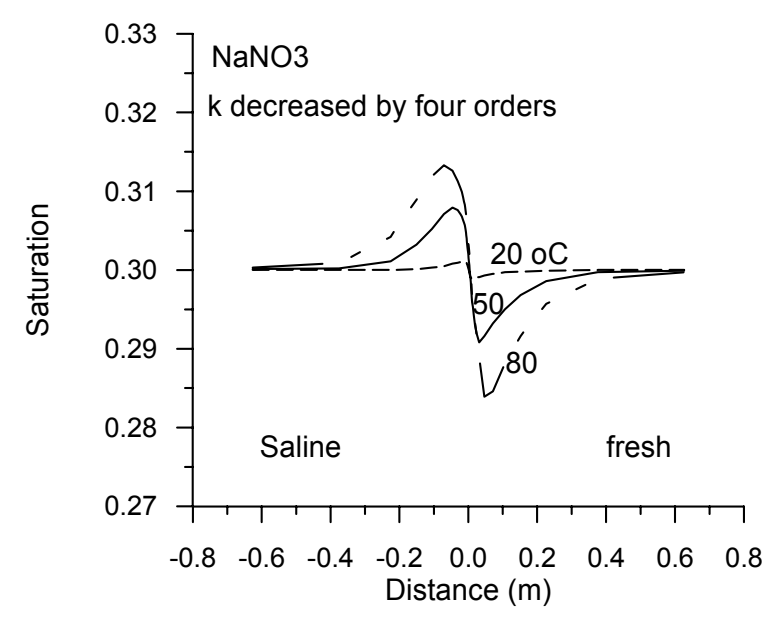

(d)

Figure 23. Water saturation obtained from different temperatures using a salt mass fraction of 0.2 .

\subsection{Time evolution}

To study the time evolution of this salinity-driven fluid flow, we used (1) an intermediate permeability value (or decreased by two orders of magnitude), (2) an intermediate temperature of $50{ }^{\circ} \mathrm{C}$, and (3) both $\mathrm{NaCl}$ and $\mathrm{NaNO}_{3}$ solutions with a mass 
fraction of 0.2 . Results in terms of water saturation and salt concentration are presented in Figures 24 and 25. A water saturation peak develops very rapidly (Figure 24) because the initial salt concentration gradient is very sharp. This is consistent with the laboratory experiments of Weisbrod et al. (2000) who reported that significant transport of water from pre-wetted sand into the highly saline $\mathrm{NaNO}_{3}$ solution plumes takes place within hours. The saturation peak propagates gradually to the inside of the saline region, with little change in magnitude. The propagation rate decreases over time because the salt concentration gradient is getting smaller due to salt advection and diffusion in the liquid phase.

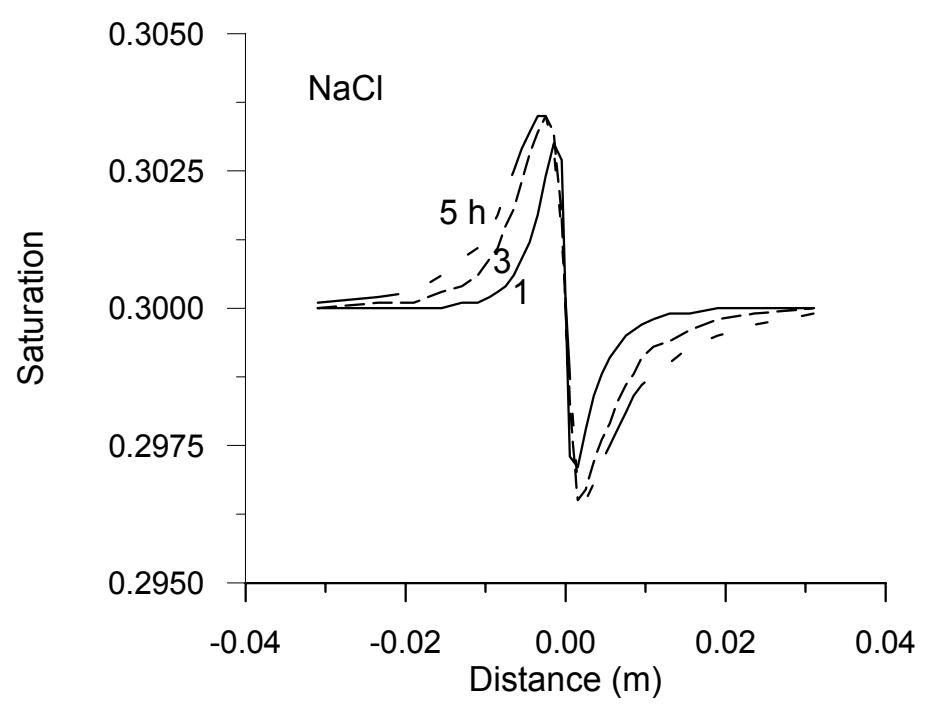

Figure 24. Water saturation at 1,3 , and 5 hours obtained using a $\mathrm{NaCl}$ mass fraction of 0.2 , a permeability decreased by two orders of magnitude, and a temperature of $50^{\circ} \mathrm{C}$. 


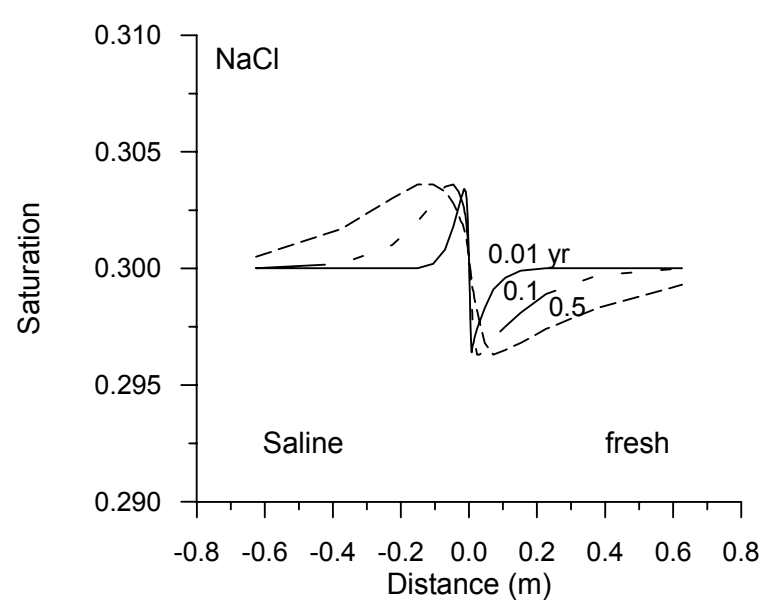

(a)

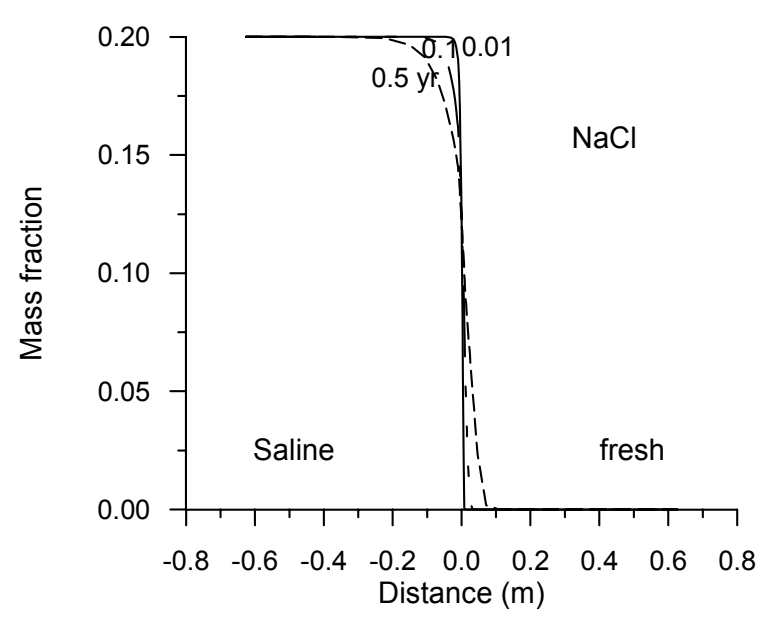

(c)

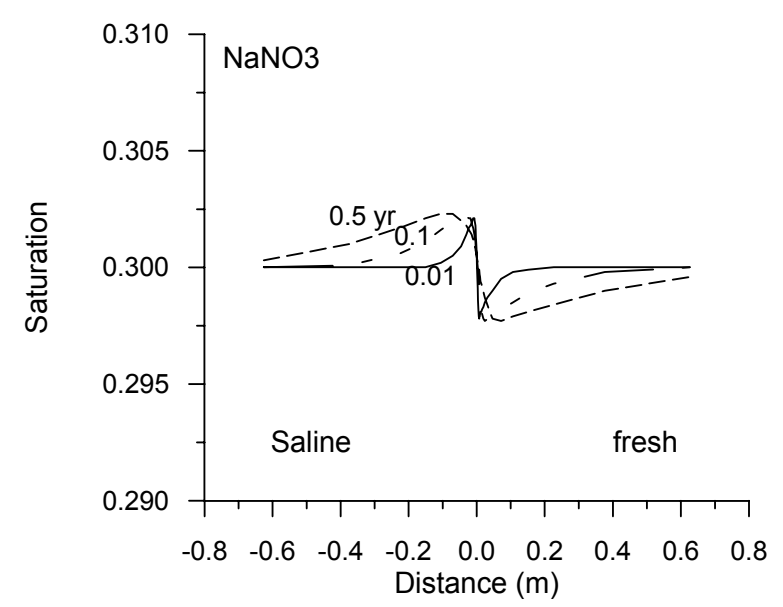

(b)

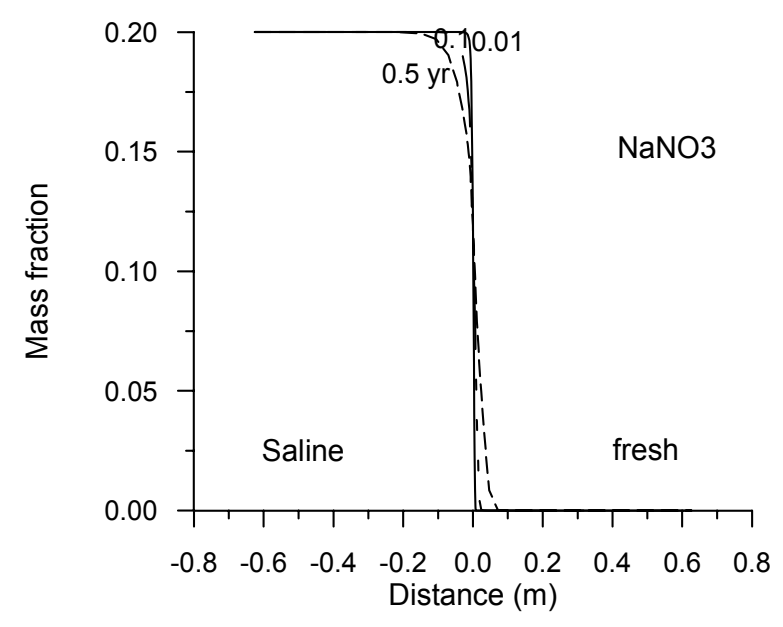

(d)

Figure 25. Water saturation and salt mass fraction at various times obtained using a salt mass fraction of 0.2 , a permeability decreased by two orders of magnitude, and a temperature of $50{ }^{\circ} \mathrm{C}$. 


\section{Conclusions}

We have presented functional relationships of salinity and temperature dependent thermophysical properties (density, viscosity, and vapor pressure) of $\mathrm{NaNO}_{3}$ solutions. We have compared thermophysical properties of $\mathrm{NaNO}_{3}$ solutions with those of $\mathrm{NaCl}$ solutions in terms of both mass fraction and mole fraction. It has been found that in terms of mass fraction density of $\mathrm{NaNO}_{3}$ solution is close to that of $\mathrm{NaCl}$ solutions, while in terms of mole fraction viscosities of both salt solutions are close. Vapor pressures of both solutions decrease with increasing salt concentration (vapor pressure lowing effect). We have implemented the thermophysical property correlations for $\mathrm{NaNO}_{3}$ solutions into a new TOUGH2 equation-of-state module EWASG_NaNO 3 , which is modified from the previous TOUGH2 equation-of-state module EWASG for $\mathrm{NaCl}$.

Vapor pressure lowering due to salinity results in vapor diffusion from fresh water to saline regions, increasing water saturations in the saline regions, and inducing capillary-driven liquid flow towards the fresh water. Using these two modules of the TOUGH2 simulator, we have simulated a one-dimensional problem to study this salinitydriven fluid flow in unsaturated media. Significant effects occur rapidly (hours) over rather small spatial scales $(\mathrm{mm}$ to $\mathrm{cm})$, requiring very fine space discretization. Through numerical experiments, we have investigated conditions and parameters (including heat conduction, permeability, and temperature) controlling these processes. Heat conduction plays a very important role in this salinity-driven vapor diffusion, maintaining a nearly constant temperature even though the process involves considerable latent heat effects. 
Therefore, the problem can be adequately simulated using isothermal conditions. The decreased permeability reduces water mobility, but it increases the strength of capillary pressure. Overall the permeability effect dominates, and for smaller permeability more net water transfer occurs towards the saline region. Nevertheless, the decreased permeability effect on water flow is also complicated with accordingly decreased tortuosity effect on vapor diffusion. The higher the temperature, the more significant the salinity-driven fluid flow. At lower temperatures (below $50{ }^{\circ} \mathrm{C}$ ) the salinity-driven fluid flow of $\mathrm{NaCl}$ solutions is more pronounced, but at higher temperatures (such as $80{ }^{\circ} \mathrm{C}$ ) that of $\mathrm{NaNO}_{3}$ solution is more significant. Water saturation peak develops very rapidly because of initial sharp salt concentration gradient between the saline and fresh sides. The peak propagates gradually to the inside of the saline region. The propagation rate decreases with increasing time because salt concentration gradient is getting smaller due to salt advection and diffusion in the liquid phase.

Acknowledgement. We thank to Huihai Liu and Stefan Finsterle for a review of the manuscript and suggestions for improvement. This work was supported by the U.S. Department of Energy under Contract No. DE-AC03-76SF00098 through Memorandum Purchase Order 248861-A-B2 between Pacific Northwest National Laboratory and Lawrence Berkeley National Laboratory.

\section{References}

Adamson, A.W., 1990, Physical chemistry of surfaces, John Wiley \& Sons, New York. Apelblat, A., and Korin, K.: 1988, The vapor pressures of saturated aqueous solutions of sodium chloride, sodium bromide, sodium nitrate, sodium nitrite, potassium iodate, 
and rubidium chloride at temperatures from $227 \mathrm{~K}$ to $323 \mathrm{~K}, J$. Chem. Thermodynamics, 30, 59-71.

Battistelli, A., Calore, C., and Pruess, K.: 1997, The simulator TOUGH2/EWASG for modeling geothermal reservoirs with brines and non-condensible gas, Geothmics, 26 (4), 437-464.

Isono, T.: 1984, Density, viscosity and electrolytic conductivity of concentrated aqueous electrolyte solutions at several temperatures, Alkaline-earth chlorides, $\mathrm{LaCl}_{3}, \mathrm{Na}_{2} \mathrm{SO}_{4}$, $\mathrm{NaNO}_{3}, \mathrm{NaBr}, \mathrm{KNO}_{3}, \mathrm{KBr}$, and $\mathrm{Cd}\left(\mathrm{NO}_{3}\right)_{2}$, J. Chem. Eng. Data, 29, 45-52.

Khaleel, R., and Freeman, K.J., 1995, Variability and scaling of hydraulic properties for 200 area soils, Hanford Site, report WHC-EP-0883, Westinghouse Hanford Company, Richland, WA.

Leverett, M. C., 1941, Capillary behavior in porous solids, Trans. Soc. Pet. Eng. AIME, $142,152-169$.

Mahiuddin, S., and Ismail, K.: 1996, Temperature and concentration dependence of the viscosity of aqueous sodium nitrate and sodium thiosulphate electrolytic systems, Fluid phase equilibria, 123, 231-243.

Millington, R. J., and Quirk, J. P., 1961, Permeability of porous solids: Trans. Faraday Soc., v. 57, p. 1200-1207.

Narasimhan, T. N., and Witherspoon, P. A.: 1976, An integrated finite difference method for analyzing fluid flow in porous media, Water Resour. Res., 12, 57-64.

Pruess, K.: 1987, TOUGH user's guide: Nuclear Regulatory Commission, report NUREG/CR-4645 (also Lawrence Berkeley Laboratory Report LBL-20700, Berkeley, California).

Pruess, K.: 1991, TOUGH2: A general numerical simulator for multiphase fluid and heat flow, Lawrence Berkeley Laboratory Report LBL-29400, Berkeley, California, 37 pp.

Pruess, K., Oldenburg, C., and Moridis, G.: 1999, TOUGH2's user's guide, Version 2.0, Lawrence Berkeley Laboratory Report LBNL-43134, Berkeley, California, 198 pp.

Vargaftik, N. B.: 1975, Tables on the thermophysical properties of liquids and gases: Second edition, John Wiley and Sons, New York. 
Van Genuchten, M. T.: 1980, A closed-form equation for predicting the hydraulic conductivity of unsaturated soils: Soil Science Society American Journal, v. 44, p. 892-898.

Weisbrod, N., McGinnis, T., and Selker, J.: 2000, Infiltration mechanisms of highly saline solutions and possible implications for the Hanford site, Abstract, AGU 2000 Fall meeting F411, San Francisco, California.

Weast, R. C., (Editor): 1985, Handbook of Chemistry and Physics, $66^{\text {th }}$ edn., CRC Press, FL, USA, p. D257-D260. 


\section{Appendix A. Fitted curves}

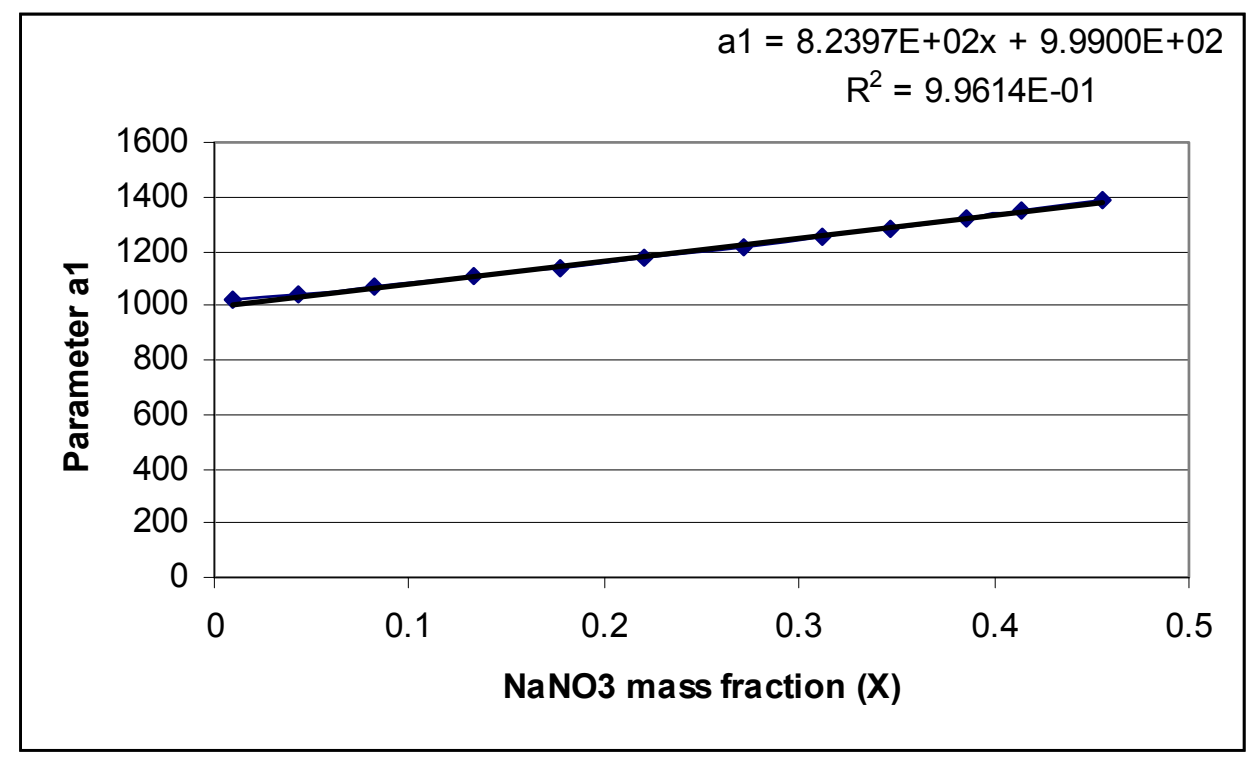

(a) Linear relationship

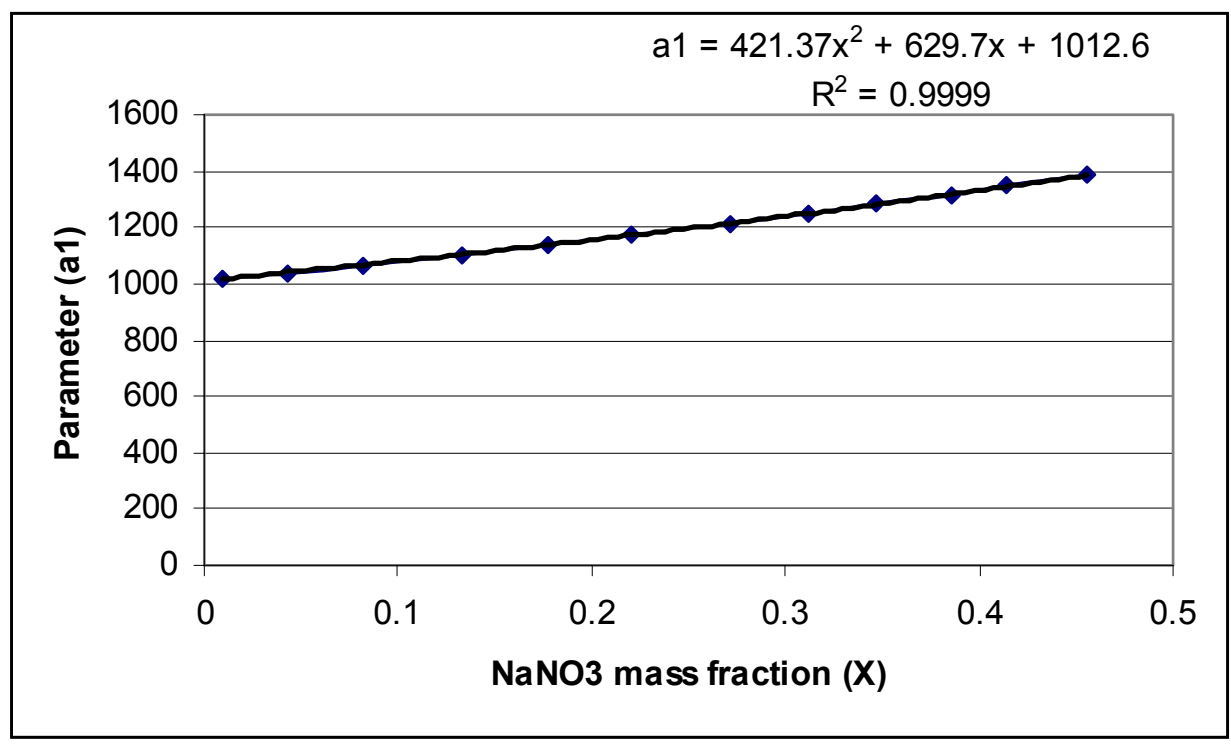

(b) Second-order polynomial

Figure A.1. The fitted parameter, $\mathrm{a}_{1}$, as a function of mass fraction, $\mathrm{X}$. 


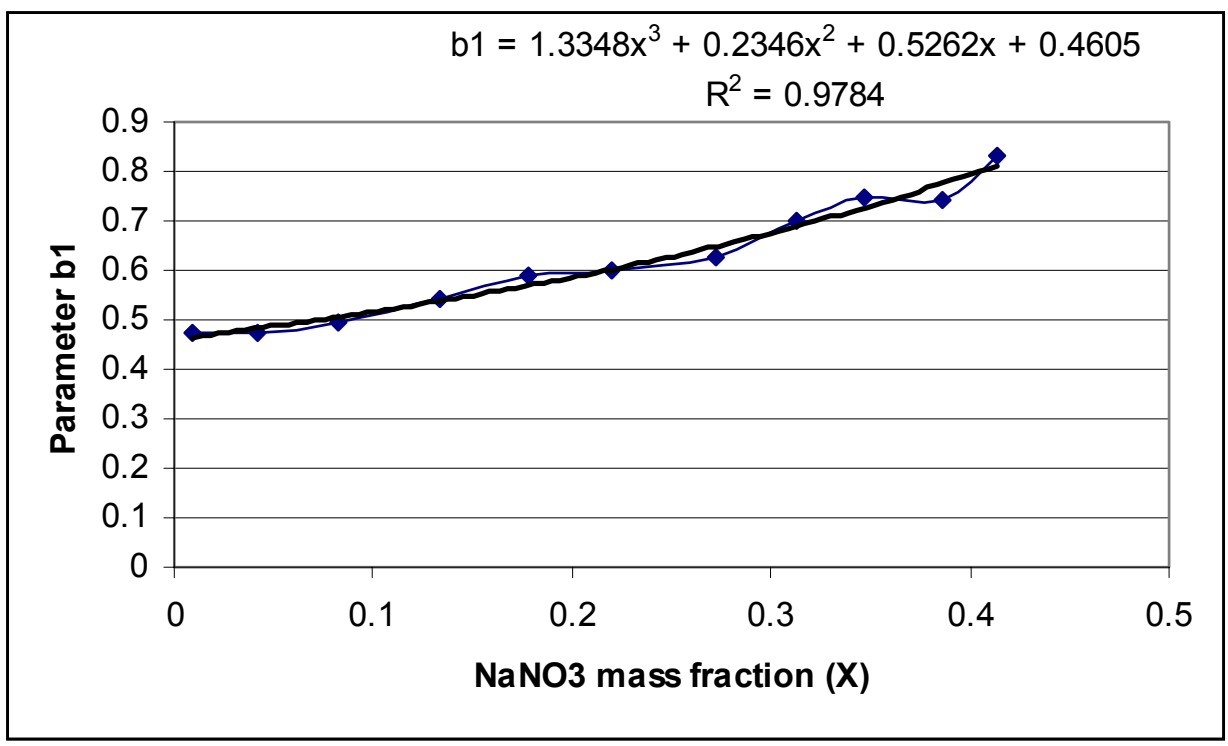

(a) Third-order polynomial

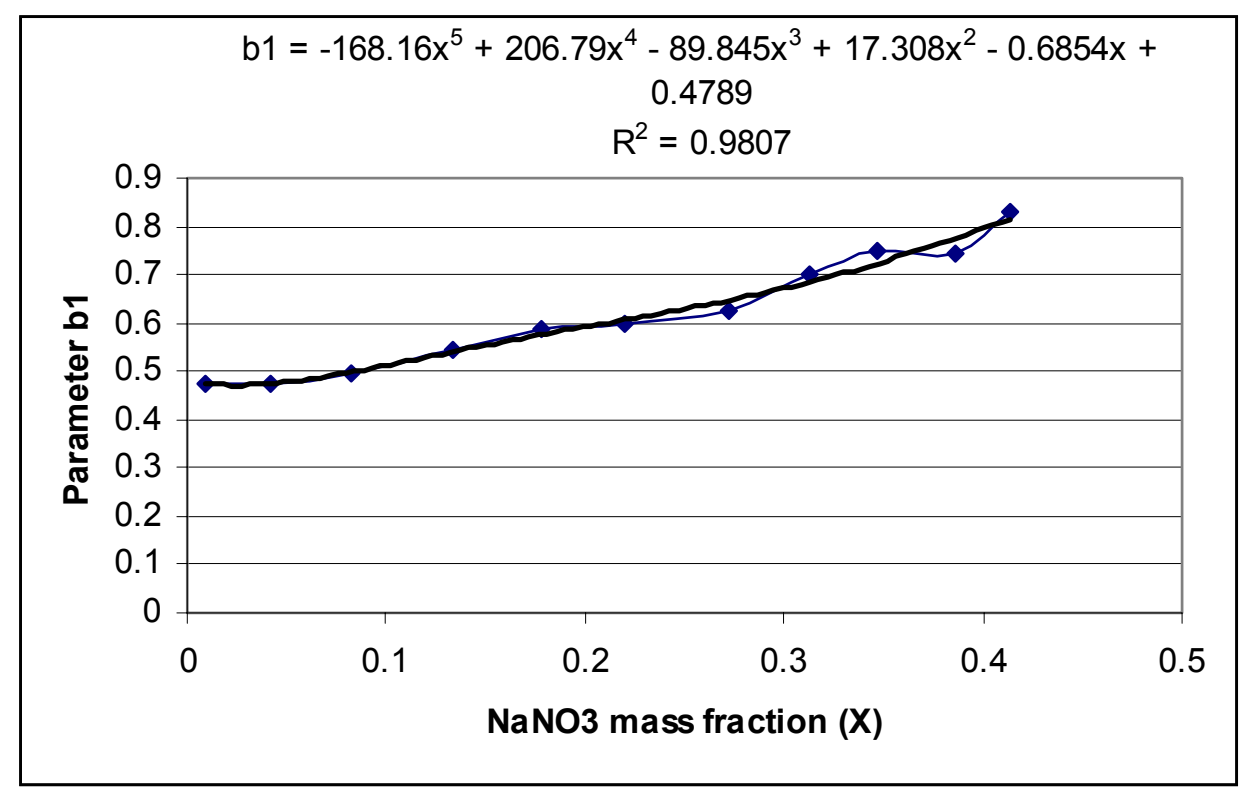

(b) Fifth-order polynomial

Figure A.2. The fitted parameter, $b_{1}$, as a function of mass fraction, $X$. 


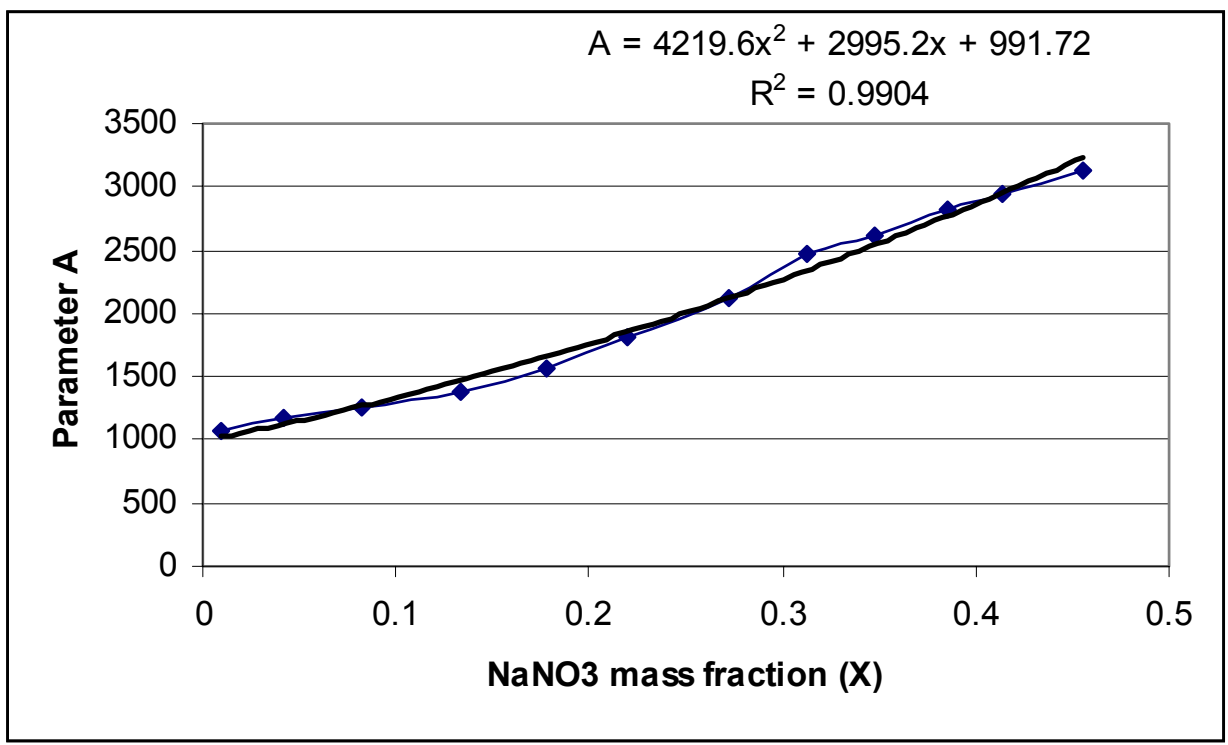

(a) Second-order polynomial

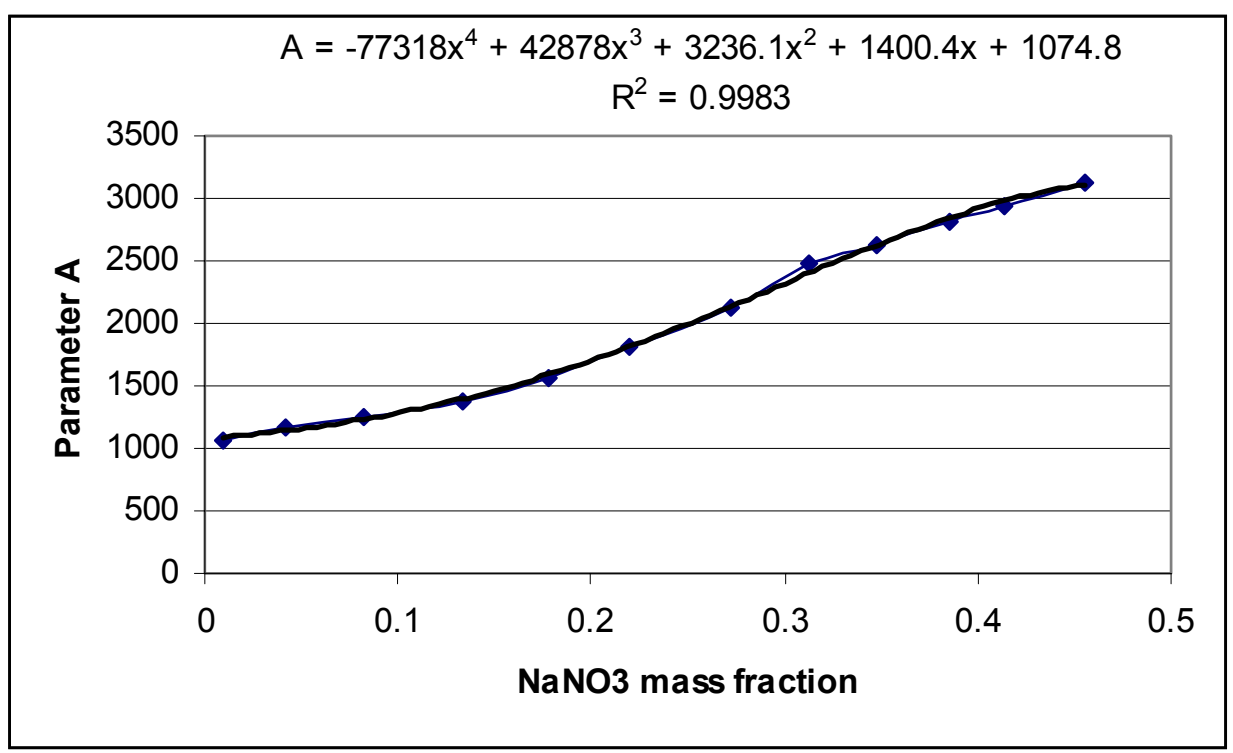

(b) Fourth-order polynomial

Figure A.3. The fitted parameter, A, as a function of mass fraction, X. 


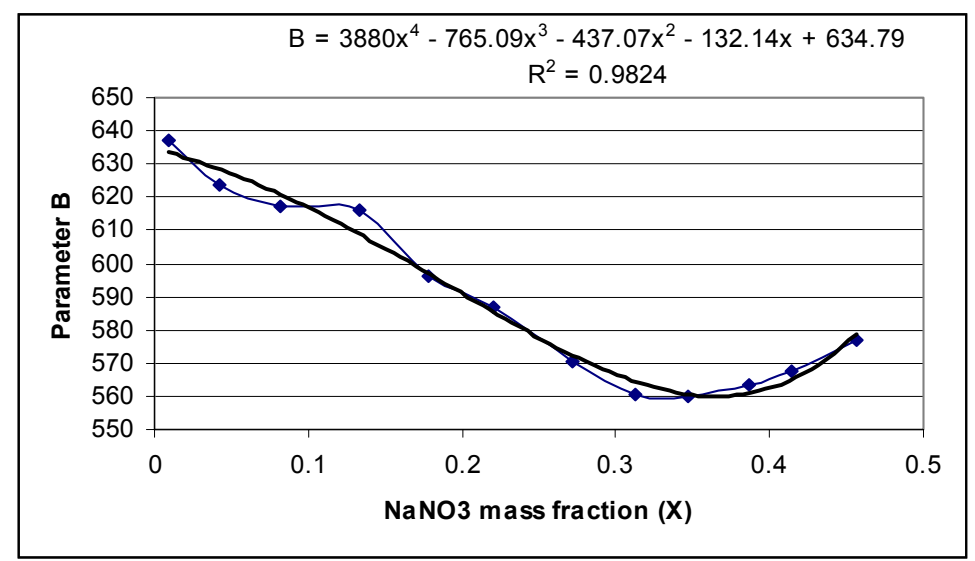

(a) Fourth-order polynomial

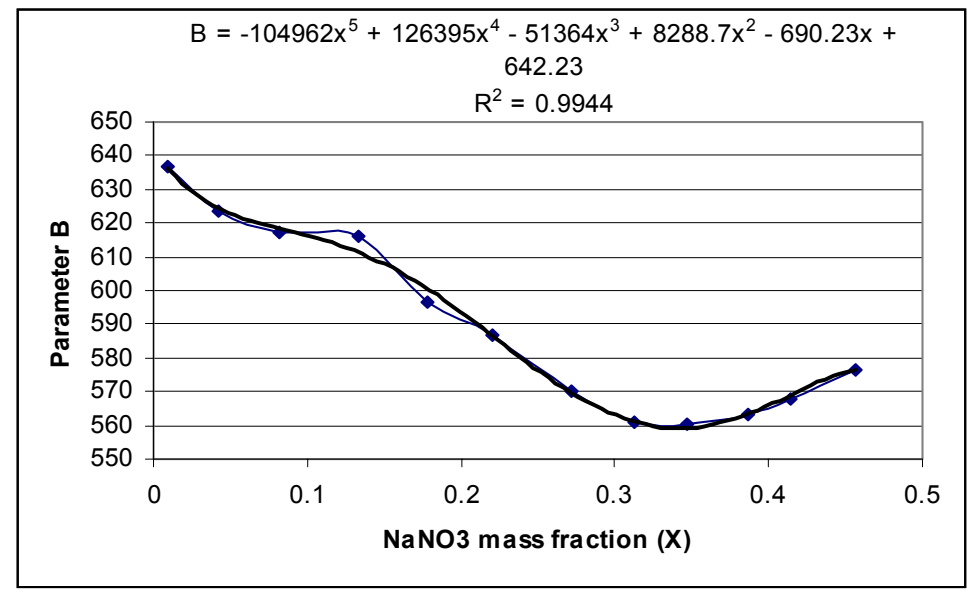

(b) Fifth-order polynomial

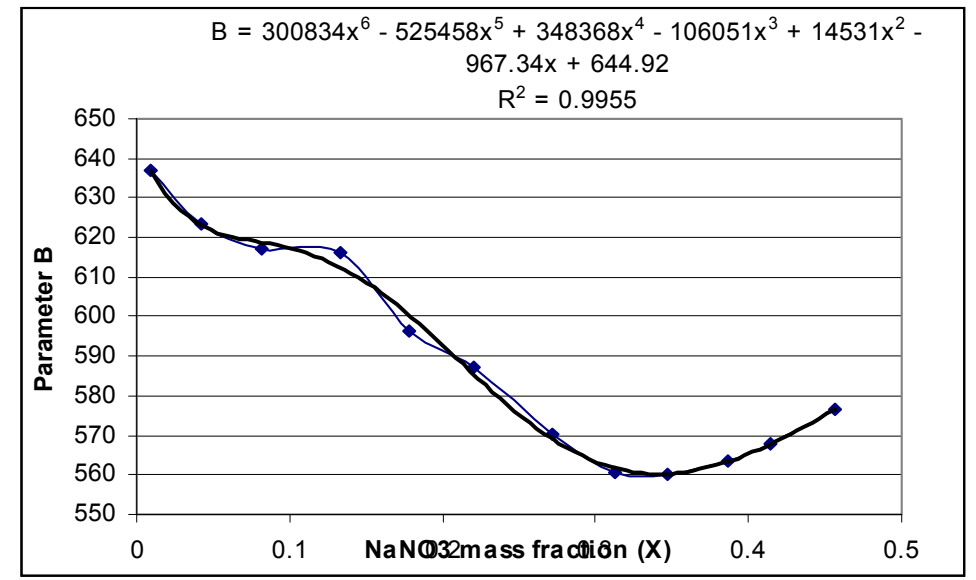

(c) Sixth-order polynomial

Figure A.4. The fitted parameter, B, as a function of mass fraction, X. 


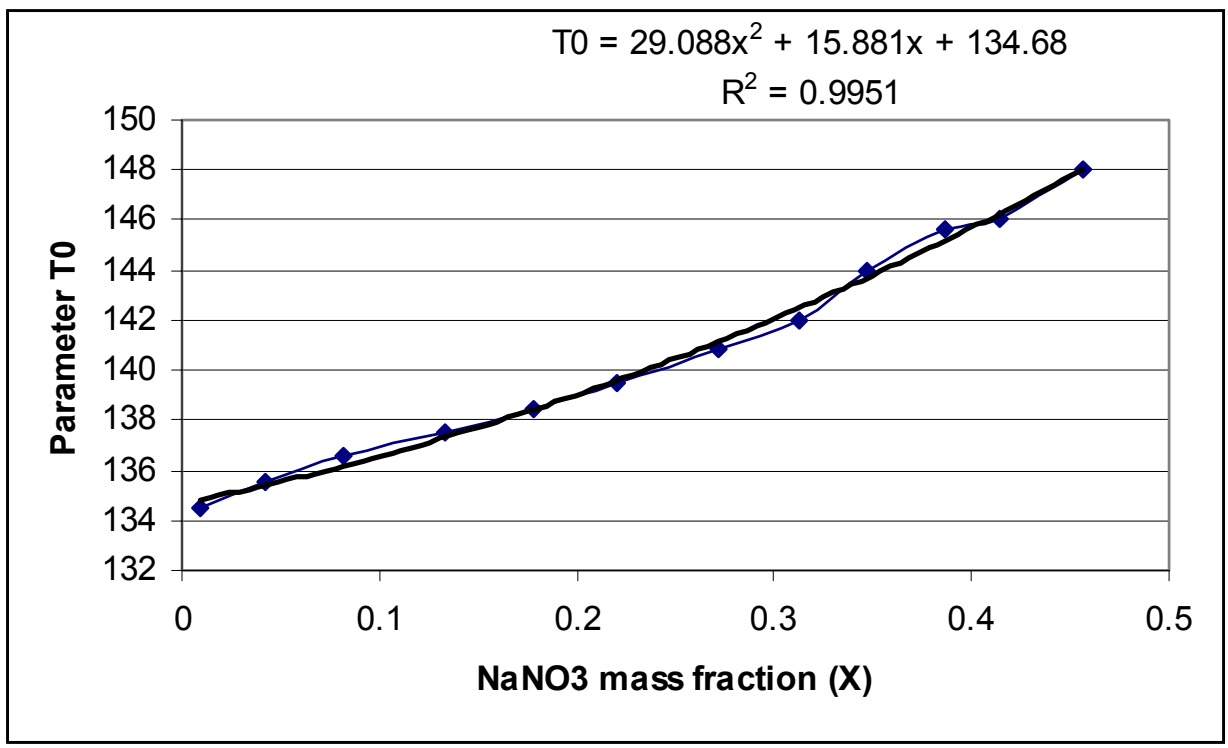

(a) Second-order polynomial

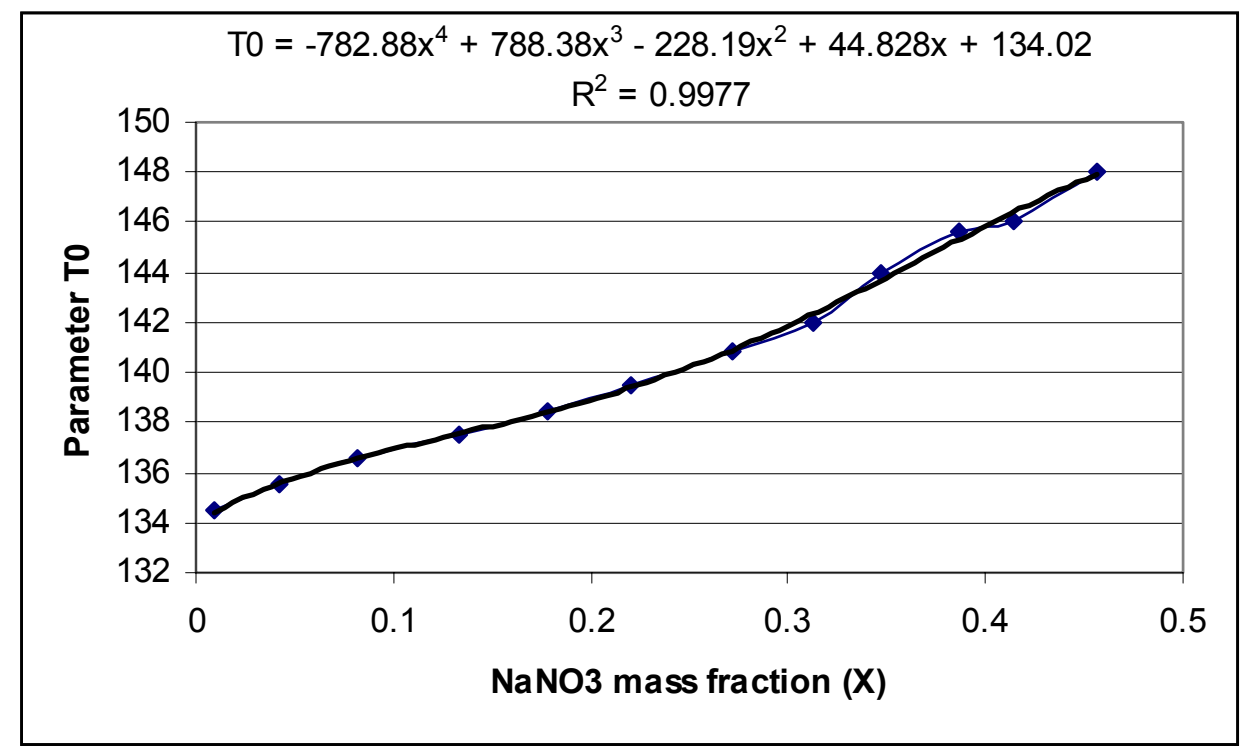

(a) Fourth-order polynomial

Figure A.5. The fitted parameter, $\mathrm{T}_{0}$, as a function of mass fraction, $\mathrm{X}$. 


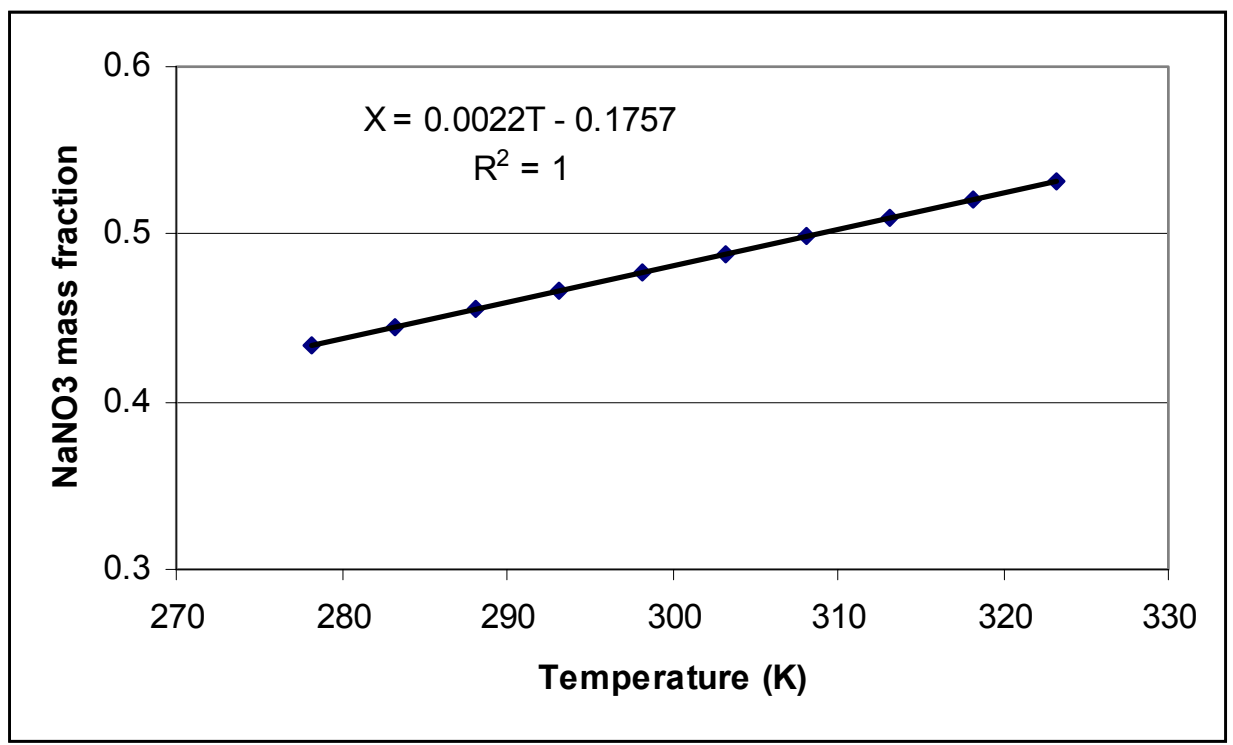

Figure A.6. Mass fraction as function of temperature for saturated $\mathrm{NaNO}_{3}$ solutions.

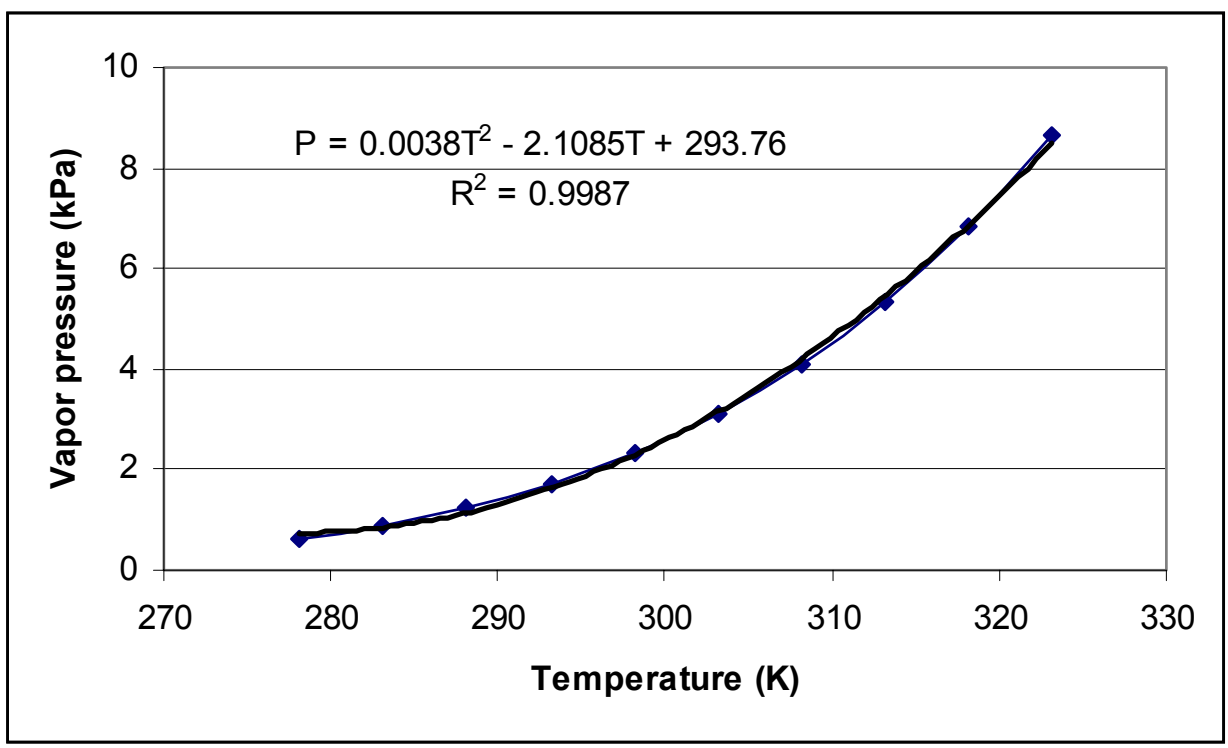

Figure A.7. Vapor pressure as function of temperature for saturated $\mathrm{NaNO}_{3}$ solutions. 


\section{Appendix B. Mass fraction and mole fraction relationship.}

Consider $1000 \mathrm{~g}$ of water with dissolved salt, containing a total number of moles $\mathrm{T}_{\text {mol }}$, of which a fraction $\mathrm{x}_{\mathrm{s}}$ is salt. We have

$$
\begin{gathered}
\mathrm{x}_{\mathrm{s}}=\frac{\mathrm{x}_{\mathrm{s}} \mathrm{T}_{\mathrm{mol}}}{\mathrm{x}_{\mathrm{s}} \mathrm{T}_{\mathrm{mol}}+\frac{1000}{\mathrm{~W}_{\mathrm{w}}}} \\
\mathrm{T}_{\mathrm{mol}}=\frac{\frac{1000}{1-\mathrm{W}_{\mathrm{w}}}}{1} \\
\mathrm{X}_{\mathrm{S}}=\frac{\mathrm{x}_{\mathrm{s}} \mathrm{T}_{\mathrm{mol}} \mathrm{W}_{\mathrm{s}}}{\mathrm{x}_{\mathrm{s}} \mathrm{T}_{\mathrm{mol}} \mathrm{W}_{\mathrm{s}}+1000}
\end{gathered}
$$

where $\mathrm{W}_{\mathrm{w}}$ is water molecular weight (18.01528), $\mathrm{W}_{\mathrm{S}}$ is salt molecular weight $(58.448$ for $\mathrm{NaCl}$, and 84.99471 for $\mathrm{NaNO}_{3}$ ), and $\mathrm{X}_{\mathrm{s}}$ is the salt mass fraction. If we know the mole fraction of salt, we can calculate the corresponding mass fraction.

If we know mass fraction $\mathrm{X}_{\mathrm{S}}$, the procedure for calculating mole fraction $\mathrm{x}_{\mathrm{S}}$ is given in the following. By substituting (B2) into (B3) and rearranging, we have

$$
\mathrm{X}_{\mathrm{S}}=\frac{\mathrm{X}_{1}}{\mathrm{X}_{1}+1}
$$

where

$$
\mathrm{X}_{1}=\frac{\mathrm{W}_{\mathrm{S}}}{\mathrm{W}_{\mathrm{w}}} \frac{\mathrm{x}_{\mathrm{s}}}{1-\mathrm{x}_{\mathrm{s}}}
$$

From (B4), we have 


$$
X_{1}=\frac{X_{S}}{1-X_{S}}
$$

From (B5), we have

$$
\mathrm{x}_{\mathrm{s}}=\frac{\frac{\mathrm{W}_{\mathrm{w}}}{\mathrm{W}_{\mathrm{S}}} \mathrm{X}_{1}}{1+\frac{\mathrm{W}_{\mathrm{w}}}{\mathrm{W}_{\mathrm{S}}} \mathrm{X}_{1}}
$$

We first obtain value of $\mathrm{X}_{1}$ from (B6). Then we obtain $\mathrm{x}_{\mathrm{s}}$ from (B7). 